Review

\title{
Lockheed Martin-A Short Review
}

\author{
${ }^{1}$ Relly Victoria Petrescu, ${ }^{2}$ Raffaella Aversa, ${ }^{3}$ Bilal Akash, ${ }^{4}$ Ronald Bucinell, \\ ${ }^{5}$ Juan Corchado, ${ }^{2}$ Antonio Apicella and ${ }^{1}$ Florian Ion Tiberiu Petrescu \\ ${ }^{1}$ ARoTMM-IFToMM, Bucharest Polytechnic University, Bucharest, (CE), Romania \\ ${ }^{2}$ Advanced Material Lab, Department of Architecture and Industrial Design, \\ Second University of Naples, 81031 Aversa (CE), Italy \\ ${ }^{3}$ Dean of School of Graduate Studies and Research, American University of Ras Al Khaimah, UAE \\ ${ }^{4}$ Union College, USA \\ ${ }^{5}$ University of Salamanca, Spain
}

Article history

Received: 20-04-2017

Revised: 09-05-2017

Accepted: 30-05-2017

Corresponding Author: Florian Ion T. Petrescu ARoTMM-IFToMM, Bucharest Polytechnic University, Bucharest, (CE), Romania

Email: scipub02@gmail.com
Abstract: Lockheed Martin is a company aerospace global American, defense, security and advanced technologies with interests in the world. Has been formed by the merger of Lockheed with Martin Marietta in March 1995. Has its head office in Bethesda, Maryland, in the area of Washington DC. Lockheed Martin has 126,000 employees in the entire world. Marillyn Hewson is the current President and Chief Executive Officer. Lockheed Martin is one of the biggest companies in the aerospace and defense and technologies. Is the largest contractor for the defense of the world based on revenue for the fiscal year 2014. In 2013, $78 \%$ of the revenue to Lockheed Martin has come from military sales; this was the main list of contractors with the federal government and the American has received almost $10 \%$ of the funds paid by the Pentagon. In 2009, the contracts of the American government were represented by 38.4 billion dollars $(85 \%)$, the contracts of foreign governmental with 5.8 billion dollars (13\%) and the trade contracts and other contracts for 900 million dollars (2\%). Lockheed Martin operates in five segments of activity: Aeronautics, information systems and global solutions, missiles and control systems of the fire, rotating systems and the mission and space-based systems. The company received six times Collier County Trophy, including in 2001 in order to be part of the development of the propulsion system X-35/F-35B LiftFan and most recently in 2006 to lead the team that has developed the plane to fight F-22 Raptor. Lockheed Martin is currently developing F-35 Lightning II and lead the international chain of supply, leads the team for the development and implementation of technology solutions for the new SpaceFence (replacement AFSSS USAF) and is the main contractor for the development of the control module (Orion spaceship). The company invests also in the systems of health systems, renewable energy, intelligent distribution of energy and nuclear fusion compact.

Keywords: Lockheed Martin, Aerospace, Spacecraft Propulsion, Chemical Rockets, Jet Engines, Satellites, Electric Propulsion

\section{Introduction}

Lockheed Martin is a company aerospace global American, defense, security and advanced technologies with interests in the world. It has been formed by the merger of Lockheed with Martin Marietta in March
1995. Has its head office in Bethesda, Maryland, in the area of Washington DC. Lockheed Martin has 126,000 employees in the entire world. Marillyn Hewson is the current President and Chief Executive Officer (Lockheed Martin, From Wikipedia).

Lockheed Martin is one of the biggest companies in 
the aerospace and defense and technologies. Is the largest contractor for the defense of the world based on revenue for the fiscal year 2014. In 2013, 78\% of the revenue to Lockheed Martin has come from military sales; this was the main list of contractors with the federal government and the American has received almost $10 \%$ of the funds paid by the Pentagon. In 2009 , the contracts of the American government were represented by 38.4 billion dollars (85\%), the contracts of foreign governmental with 5.8 billion dollars (13\%) and the trade contracts and other contracts for 900 million dollars $(2 \%)$.

Lockheed Martin operates in five segments of activity: Aeronautics, information systems and global solutions, missiles and control systems of the fire, rotating systems and the mission and space-based systems. The company received six times Collier County Trophy, including in 2001 in order to be part of the development of the propulsion system X-35/F-35B LiftFan and most recently in 2006 to lead the team that has developed the plane to fight F-22 Raptor. Lockheed Martin is currently developing F-35 Lightning II and lead the international chain of supply, leads the team for the development and implementation of technology solutions for the new SpaceFence (replacement AFSSS USAF) and is the main contractor for the development of the control module (Orion spaceship). The company invests also in the systems of health systems, renewable energy, intelligent distribution of energy and nuclear fusion compact (Petrescu and Petrescu, 2011; 2012; 2013a; 2013b; 2013c; Mirsayar et al., 2017).

He talks held by the merger of Lockheed Corporation and Martin Marietta was started in March 1994, the companies announcing the merger planned by 10 billion dollars on 30 August 1994. The contract has been completed on 15 March 1995, when the shareholders of the two companies have approved the merger. The segments of the two companies which have not been retained by the new company formed the basis for the incumbent communicated L-3, a contractor for the defense sized, by itself.

Lockheed Martin also later stole the material of the company Martin Marietta Materials.

Both companies have contributed with important products to the new portfolio. Products Lockheed have included the missile Trident, P-3 Orion, F-16 Fighting Falcon, F-22 Raptor, C-130 Hercules,-4would Fightinghawk and satellite DSCS-3. Products Martin Marietta have included the rockets Titan, Sandia National Laboratories (management contract purchased in 1993), External Tank Shuttle, Viking 1 and Viking 2, Transfer Blinded Stage (under the subcontracting to Orbital Sciences Corporation) and various types of satellite.

On the date of 22 April 1996, Lockheed Martin has completed the purchase of firms from Corporation for the electronics industry of defense and systems of systems integration for the sum of 9.1 billion dollars, business being announced in January. The rest from his has become From Space and Communications. Lockheed Martin abandoned the plans for a fusion of 8.3 billion dollars with Northrop Grumman on 16 July 1998, because of the concerns of the government from the power of the potential of the new group; Lockheed/Northrop would have had control over $25 \%$ of the budget of the department for defense.

For Mars Climate Orbiter, Lockheed Martin has provided in incorrectly NASA with software which used the measurements in units of the usual force of the USA, when it was expected a value metric; this has led to the loss of Orbiter at a cost of 125 million dollars with the ship development of a cost 193,1 million dollars.

In May 2001, Lockheed Martin has sold Lockheed Martin Control Systems by BAE Systems. On 27 November 2000, Lockheed has concluded the sale of its activity of the electronic systems for aerospace by BAE Systems for 1.67 billion dollars, transaction announced in July 2000. This group has included Sanders Associates, Fairchild Systems and Lockheed Martin Space Electronics and Communications. In 2001, Lockheed Martin has won the contract for the construction of F-35 Lightning II; this was the greatest project of purchases of aircraft of the battle at F-16, with an initial 3,000 of aircraft. In 2001, Lockheed Martin has established a new investigation carried out by the office of the inspector general of the NASA, with the assistance of the Agency in respect of the audit of the contracts of defense. The company has paid to the Government of the United States the sum of 7.1 million dollars, based on the statements according to which its predecessor, Lockheed Engineering Science Corporation, claims submitted false statements concerning the rental costs by NASA.

On 12 May 2006, The Washington Post has reported that when Robert Stevens has taken control of his Lockheed Martin in 2004, he faced with a dilemma that in ten years, 100000 of the 78,000 employees of Lockheed Martin - more than three-quarters - he would withdraw. On 31 August 2006, Lockheed Martin has won a contract of 3.9 billion dollars from NASA to the design and construction of the woman, hereinafter referred to as the latest Orion for missile Ares I in the constellation program. In 2009, NASA has reduced the requirements of the crew of the first six places to four for the carriage to the International Space Station.

The Lockheed Martin's Center for Leadership Excellence (CLE) was building in Bethesda, Maryland (Fig. 1).

On 13 August 2008, Lockheed Martin has acquired the governmental unit of the company Nantero, Inc., a company that has developed the methods and processes for nanotubes incorporation of carbon in the electronic devices the last generation. In 2009, Lockheed Martin bought Unitech (Lockheed Martin, From Wikipedia). 


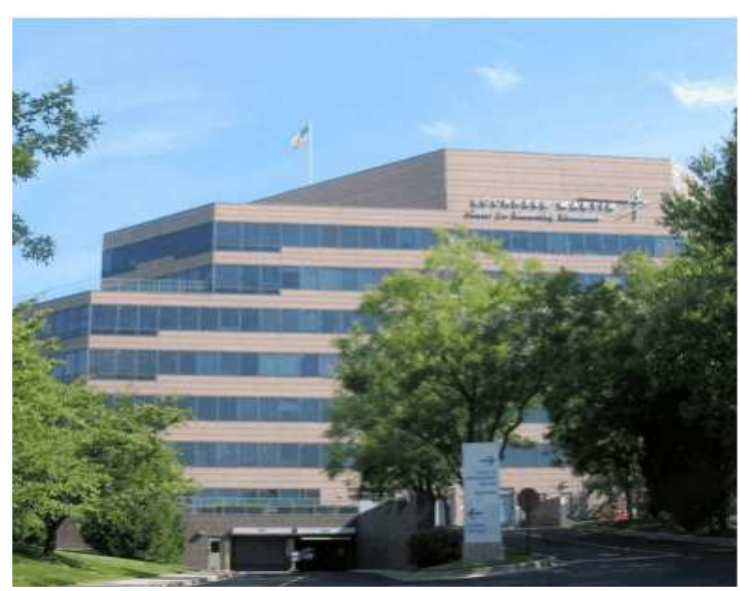

Fig. 1. Lockheed Martin's Center for Leadership Excellence (CLE) Building in Bethesda, Maryland Source: https://en.wikipedia.org/wiki/Lockheed_Martin\#/media /File:Lockheed_Martin_headquarters.jpg

\section{Methods and Materials}

On November 18, 2010, Lockheed Martin has announced that it will close its location, Eagan Minnesota until 2013, to reduce costs and optimize the capacity at its locations at national level. In January 2011, Lockheed Martin has agreed to pay the U.S. Government 2 million dollars to settle the accusations that the company has submitted to the false complaints concerning a governmental contract in the U.S. for that amount. The statements came from a contract with the center of the communal resources of the Major Support for Oceanographic of Mississippi riverboat casino. The date of 25 May 2011, Lockheed Martin has purchased the first system to the quantum computing from D-Wave Systems. Lockheed Martin and D-Wave will collaborate to realize the benefits of platforms based on a word a quantum annealing processor, applied to some of the most difficult problems in the calculation of his Lockheed Martin. Lockheed Martin has established a contract over several years which includes a system, maintenance and services (Potentially a milestone an important matter to both companies; Aversa et al., 2016a; 2016b; 2016c; 2016d; 2016e; 2016f; Mirsayar et al., 2017).

The date of 28 May 2011 has been reported as an attack have risen who has used EMC files stolen above has been broken in the materials that are sensitive to the contractor. It is not clear whether the fault Lockheed is the specific request by which, on 1 June 2011, new military strategy of the United States, explains explicitly that a had though-attack is oval face for a traditional act of war.

On 10 July 2012 Lockheed Martin announced that reduces its workforce with 740 workers to reduce costs in order to remain competitive, as necessary to increase in the future. On 2 August 2012, Vice President for business development, George
Standridge, said that the company has offered other 6 aircraft C-130J air forces Indian, for which is located in the discussion with the Indian government. In November 27 2012, Lockheed Martin has announced that Marillyn Hewson will become the executive director of the corporation on 1 January 2013.

In the date of 7 January 2013, Lockheed Martin Canada has announced that it will acquire the maintenance, repair and revision of the assets of the motor of the Aveo Performance Fleet Performance in Montreal, Canada. In July 3 2013, Lockheed Martin has announced that it has teamed up with the Dream Hammer in order to use the software company for the control and the integrated control of vehicles without air pilot. Lockheed Martin has worked with Bell Helicopter to propose the tiltrotor V-280 Valor for the program Future Elevator Vertical (FVL). In September 2013, Lockheed Martin has purchased technology company Amor Group in Scotland, stating that the agreement will help his plans to extend at international level and in the markets without defense. On 14 November 2013, Lockheed has announced that it will close down the institution of Akron Ohio, in which he will pay 500 employees and will be transferred to other employees in other locations.

In March 2014, Lockheed Martin has purchased Beontra AG, provider of integrated tools planning and predictors of application for airports, which intends to extend its business into business solutions for information technology hubs. In March 2014, Lockheed Martin and announced the purchase of Industrial Defender Inc. On 2 June 2014, Lockheed Martin got a contract the Pentagon to build a fence of space to follow the debris, leaving it from satellites and spacecraft. In September 2014, Lockheed has agreed with the sale of the 40 planes F-35 in South Korea for delivery between 2018 and 2021, for a fee in the region of 7.06 billion dollars.

20 July 2015, Lockheed Martin announced its plans to buy aircraft Sikorsky from United Technologies Corporation at a cost of 7.1 billion dollars. The Pentagon has criticized the acquisition that causing a reduction of competition. In November 2015, the acquisition has received the final approval from the Chinese government, with a total cost of 9 billion dollars. Dan Schulz was appointed president of the company Lockheed Martin Sikorsky. Lockheed Martin has shown drawings for a strategic airlifter with two trees, with the structure of the wing, similar to the dimensions of the C5. On 31 March 2015, the US marine granted to Lockheed Martin a contract worth 362 million dollars for the construction of the class Freedom.

\section{Lockheed C-130 Hercules}

Lockheed C-130 is Hercules aircraft military transport turbo-prop with four motors designed and built the original Lockheed (now Lockheed Martin; Fig. 2). 
Able to use runways and unprepared takeoffs and takeoffs, model C-130 was initially conceived as a aircraft of troops, medevac and transport of goods. Range versatile floating has been used in a variety of other roles, among which gunship (AC-130), assault, search and rescue scientific support in research, meteorological recognition, refueling airline, maritime patrol and fight airline. It is now the main tactical plane for many military forces around the world. Over forty variants and versions of Hercules, including one civil society marketed as Lockheed L-100, operating in more than 60 nations.

C-130 has entered into service with the U.S. in 1950, followed by Australia and others. During the years of service, family Hercules has participated to many military operations, civil and humanitarian operations. In 2007, the C-130 has become the fifth aircraft - after the English Electric Canberra, B-52 Stratofortress, You-95 Bear and KC Stratotanker-135 - to mark the 50 years of continuous service with the customer the original initial, The United States Air Force. C-130 Hercules is the longest military aircraft produced continuously to over 60 years, with the current updated Lockheed Martin C-130J Super Hercules.

The Korean War which began in June 1950, has shown that the transport with a piston-engine in the era of the second world war-Fairchild C-119 Flying Boxcars Douglas C-47 Skytrains and commands Curtiss biplane C46 - were unfit for modern war. Thus, on 2 February 1951, The United States Air Force have issued a general Requirement of Operation (GOR) for a new transport to Boeing Douglas, Fairchild, Lockheed Martin, Chase, North American, Northrop and Airlifts Inc. It would have a capacity of 92 passengers, 72 of troops to fight or 64 of paratroopers in a compartment which have a length of approximately $12 \mathrm{~m}$ and a height of $2 \mathrm{~m}$ and a width of 3,0 $\mathrm{m}$. Unlike the carriage derived from the carriage by air of passengers, he was to be designed from the base as a shipment of struggling with the loading of a rail hinged loading behind the catching.

A key feature was the introduction of the turbo prop engine Allison T56, developed for C-130. At that time, turboprop was a new application of the engines with the turbine which uses the exhaust gases in order to transform the propeller which offer a range of more than at speeds led by the blade in comparison with pure turbo shafts, which have been the faster but have consumed more fuel. As in the case of the helicopters in that time, such as UH-1 Huey shaft, thirty has produced much more power for their weight than engines with piston. Lockheed will subsequently be used the same engines and technologies to Lockheed L-188 Electra. The aircraft has failed financial year in Configuration to civil society, but has been adapted successfully to the plane patrol Lockheed P-3 Orion and the plane of attack submarine, where excels efficiency and resistance turboprops.

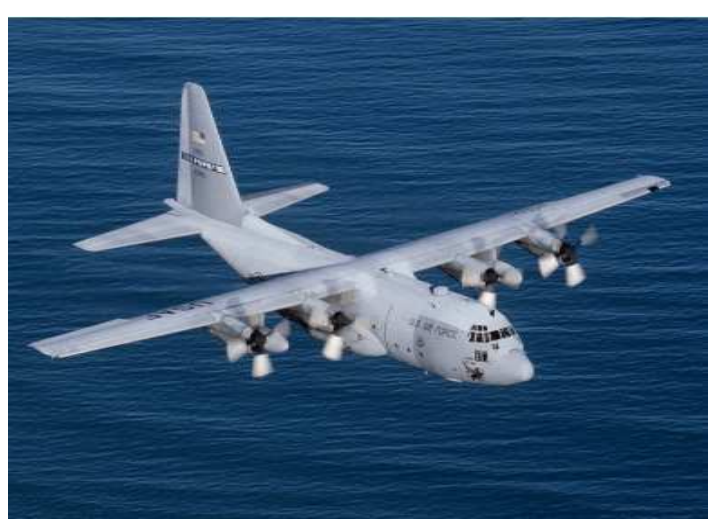

Fig. 2. Straight-wing, four-engine turboprop-driven aircraft overflying water Source: https://en.wikipedia.org/wiki/Lockheed_C-

130_Hercules\#/media/File:Lockheed_C-130_Hercules.jpg

Hercules sowed with a big brother with four motors supplier C-123, with a similar and with the injector rail freight which evolved from guitar XCG-20 Avitruc, which in turn has been designed and operated for the first time that a glider in 1947. Boeing C-97 Stratofreighter also has a rail from the rear, which made it possible to direct the vehicles on the plane (as possible and with the rail on the C-124). The rail on the Hercules was also used for the carriage of goods, which included the extraction at altitude low for Sheridan tanks and even waiving of bombs large improvised "daisy knife".

The new design of the aircraft Lockheed has had a range of 1,200 $\mathrm{nmi}$, ability to take-off to straps short and unprepared and the ability to fly with an engine closed. Fairchild, North America, Martin and Northrop have refused to attend. The other five companies have offered a total of ten projects: Lockheed Two, Boeing One, Chase Three Douglas Three and Airlifts Inc. The contest was an adventure close cooperation between the cigarette lighter of those two proposals Lockheed (preliminary design of the project L-206) and a design Douglas with four turbo prop.

The team of Lockheed design was led by Willis Benjamin Bailey, starting with a proposal for a 130 pages to Lockheed L-206. Hibbard hall, vice president and chief engineer Lockheed has seen the proposal and directed it on Kelly Johnson, who doesn't care about the aircraft with low speed and unarmed and he noticed: "If countersign the letter, you destroy the company Lockheed. " Hibbard and Johnson have signed the proposal and the company has won the contract for the Model 82 now designated on 2 July 1951.

The first flight of the prototype YC-130 has been carried out on 23 August 1954 at the factory in Lockheed Burbank, California. The aircraft, the serial number 533397, was the second prototype, but the first of the two who flew. The model YC-130 has been controlled by Stanley Beltz and Roy Wimmer in flight or $61 \mathrm{~min}$. 
toward the base of the Air Forces Edwards; Jack had real and Dick Stanton served as engineers of flight. Kelly Johnson flew to chase in a Lockheed P2V Neptune.

After they have been completed the two prototypes, production has started in Marietta, Georgia, where they have been built over 2009 2,300-130C s.

The initial model of production, the C-130A, has been supplied by the turbo prop Allison T56-A-9 with the blade with three feet and equipped initially with a red nose of types. Deliveries started in December 1956, continued until the introduction of model C-130B in 1959. Some models have been equipped with the skis and were all redesigned-130C D. As the C-130a has become operational Tactical Air Command (TAC), the lack of the range of $\mathrm{C}-130$ has become obvious and the additional capacity of fuel has been added in the form of external tanks fitted on the posts at the end of the wings.

The $\mathrm{C}-130 \mathrm{~B}$ has been developed to complete the models A previously delivered and embedded the new features, in particular an increased capacity of fuel, in the form of the auxiliary tanks constructed in the central section of the wings and an electrical system of alternating current. Standard fittings Hamilton with four paddles have replaced the helicopters with three blades Aero products which have distinguished the previous models A. C-130B had the helicopters with an impulse to the rising from $2050 \mathrm{psi}(14.1 \mathrm{MPa})$ at 3,000 psi $(21$ $\mathrm{MPa})$, as well as the engines and improved and elicile with four feet standard that have been standard up to the introduction of model $\mathrm{J}$.

A variant of the electronic recognition of the model C-130B has been designated C-130B-II. A total of 13 aircraft have been converted. The C-130B-II is distinguished by its tanks forged by the outer wing, who were reception aerials of Signals disguised restriction of Intelligence (SIGINT). These pods are slightly larger than the standard tanks wings found on other C-130B. The majority of aircraft have presented an antenna with a razor blade plugged on the body of the sensor, as well as additional aerial of the wire between the fins of the vertical and the upper body which have not been found on other C-130s. The Call out numbers radio on queue these aircraft have been changed regularly in such a way as to confuse the observers and to conceal the real mission.

The $\mathrm{C}-130 \mathrm{E}$ with extended range has entered into service in 1962, after it has been developed as a intermediate transport over long distances for military service of carriage by air. In essence, a model B, the new name was the result of installing fuel tanks Sargent external Fletcher of 1.360 dollars (5150 liters), under the middle section of each wing and turboprops Allison T56A-7A more powerful.

The pressure of the hydraulic pressure of the helicopters has been reduced to $2050 \mathrm{psi}(14.1 \mathrm{MPa})$ as a result of the weight of the external tanks in the middle of the sheer size and the wings. The model E includes and structural improvements, upgrades avionics and gross weight greater. Australia has received the delivery of 12 Hercules C130E in the period 1966-67 in order to supplement the 12 models-130C has already in service with the RAAF (Fig. 3). Sweden and Spain flies version TP-84T of the model C-130he is endowed with a capacity of fuel supply by air.

Tanks KC-130, original-130C F, procured for USMC in 1958 (under the name of the GV-1), are fitted with a fuel tank, removable 3,600 gal. The two hoses fitted with fenders and collections of fuel supply transports air up to 300 gal. Per minute (19 liters per second) to two aircraft simultaneously, thus allowing rapid cycles of training of aircraft with more handsets (a typical training of tanks of four aircraft in less than $30 \mathrm{~min}$ ). C-130G of the Merchant Navy USA has increased structural resistance, allowing an operating time of the gross weight (Lockheed C-130 Hercules, From Wikipedia).

The $\mathrm{C}-130 \mathrm{H}$ has updated turboprops Allison T56-A15 , outer wing redesigned the plane updated and other improvements minor. Later, $\mathrm{H}$ models have had a new wing of the center improved, based on fatigue, which has been retrofitted on several models $\mathrm{h}$. From the structural reasons, some models are obliged to disembark with certain quantities of fuel when transporting heavy loads, reducing the range of use. The $\mathrm{H}$ remains in the widest possible use with the forces of the United States Air (USAF) and with many forces foreign airlines. The initial deliveries have begun in 1964 (at RNZAF), while remaining production up in 1996. A C-130H improved was introduced in 1974, Australia buying 12 type in 1978 for replacing the 12 original models C-130A, in 1958. Guardian of the coastal areas in the USA uses the $\mathrm{HC}-130 \mathrm{H}$ for search and rescue over long distances, the prohibition of drugs, patrols illegal migrants, the security of the country and logistics (Fig. 4).

Models C-130H products between 1992 and 1996 have been designated as $\mathrm{C}-130 \mathrm{H} 3$ by USAF "3" indicating the third alternative design for the H Series. Enhancements include ring laser gyros, GPS receivers, a partially cockpits of glass tools (ADI and $\mathrm{H}$ ), a color radar more effectively the APN-241, a lighting device compatible with your device of visibility on the night and an integrated system for warning with missiles and rockets. Updating the electrical system has included the control units of the establishments for the generation (G) and shift units of Bus Switching Units (BSU) in order to provide a stable power components well developed (Fig. 5).

Equivalent model for export in Great Britain is the C$130 \mathrm{~K}$, also known by the Royal Air Force (RAF) as Hercules C.1. C-130H-30 (Hercules C. 3 in the service of the RAF) is a stretched version of the original Hercules, achieved by the introduction of a socket of $100 \mathrm{~cm}$ $(2.54 \mathrm{~m})$ at the rear of the cab to the pilot and a plug of $80 \mathrm{~cm}(2.03 \mathrm{~m})$ in the rear of the catching. One C-130K was bought by the Office met in order to be used by the fleet of the meteorological research, which has been classified as Hercules W.2. 


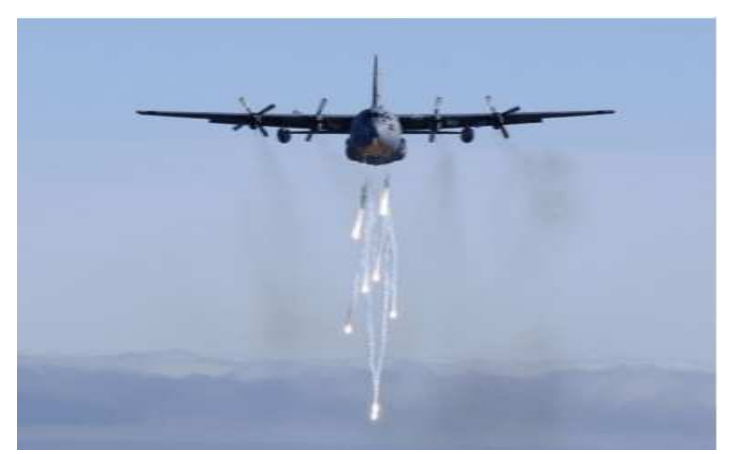

Fig. 3. A michigan air national guard C-130E dispatches its flares during a low-level training mission Source: https://en.wikipedia.org/wiki/Lockheed_C130_Hercules\#/media/File:C130 $\overline{\mathrm{E}} \_$Hercules_dropping_flares.jpg

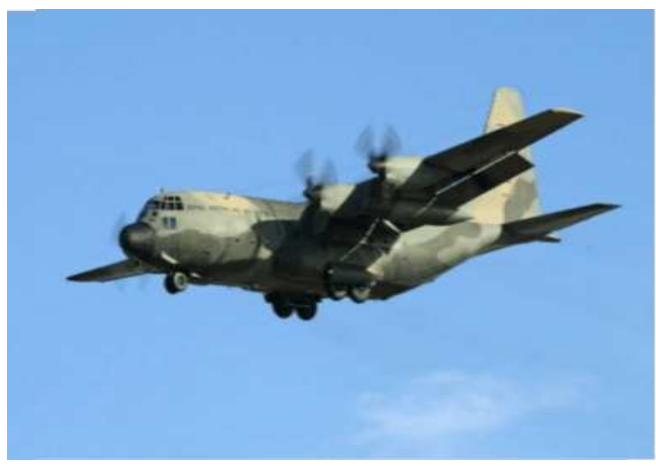

Fig. 4. Royal australian air force C-130H, 2007 Source: https://en.wikipedia.org/wiki/Lockheed_C130 Hercules\#/media/File:RAAF_Lockheed_C130

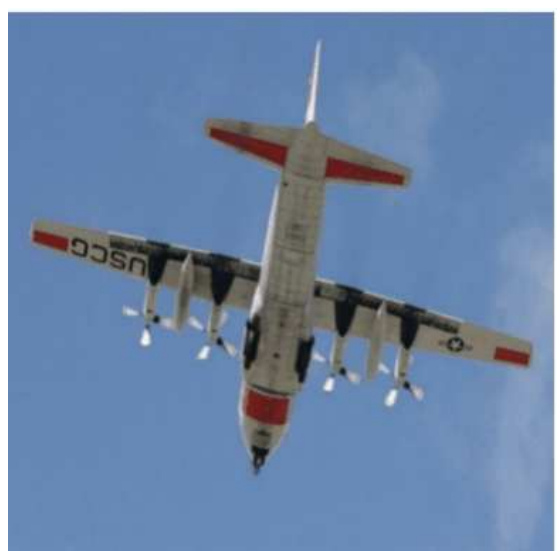

Fig. 5. United States coast guard HC-130H Source: https://en.wikipedia.org/wiki/Lockheed C130_Hercules\#/media/File:USCG_HC-130H.jpg

This aircraft has been strongly modified (with the most prominent feature being atmospheric probe long and long red on the nose and the movement of the weather radar in a pod over the catching from the front). This aircraft, called Snoopy, has been withdrawn in 2001 and was then modified by Marshall in Cambridge Aerospace as a test pilot schemes to the turbine motor A400M, TP400. C-130K is used by Falcons RAF for drops of Paratroopers Battalion. Three C-130K (Hercules C Mk.1P) have been modernized and labor sold to Austrian Airlines in 2002 (Fig. 6 and 7).

MC-130E Combat Heel has been developed for the USAF during the war in Vietnam to support the mission of special operations in the south-east Asia and has led to both MC-130H Combat Heel II and a family of other planes for special missions. 37 of the oldest models which operates in the present with the command of special operations of the Air Forces (AFSOC) are scheduled to be replaced by new versions of production MC-130J. EC-130 Commando Solo is another special missions in the framework of AFSOC, although operated only by a wing gained since the AFSOC in National Guard Pennsylvania Air and there is a Psychological Operation/Information Operation (PSYOP/IO) and TV stations that are able to send messages through the commercial frequencies. Other versions of EC-130, especially EC-130H Compass Call, there are also special variants, but are assigned to the Command to Combat Air (ACC). Gunship AC-130 has been developed for the first time during the Vietnam War to provide air support almost and other charges of attack on the ground.

HC-130 is a family of variants of search and rescue long-range used by USAF and coastal areas of security in the U.S. equipped to carry out the profound Pararescuemen (PJs, survival equipment), equipment of survival and (in the case of versions USAF) the airline has helicopters to fight, $\mathrm{HC}-130$ are usually plane for command on the spot for the SAR missions in the fight USAF only)-combat SAR (USAF and USCG). Previous versions of the USAF have been equipped and with the system of Fulton recovery on the surface of the air, designed to tow a person on the earth using a wire threaded end of a round of helium. The Film John Wayne "Green Berets" has its use. The System Fulton has been removed later when recharging the air helicopters has proven to be safer and more versatile. The Movie Perfect Storm describes a mission the actual SAR involving the airline has a National Guard New York Air HH-60G by the National Guard of aircraft New York HC-130P.

C-130R AND C-130T are US models titles and USMC, both equipped with fuel tanks externally. USN $\mathrm{C}-130 \mathrm{~T}$ is similar, but has additional enhancements in the avionics. In both models, aircraft are equipped with Allison T56-A-16. USMC versions are designated $\mathrm{KC}-130 \mathrm{R}$ or $\mathrm{KC}-130 \mathrm{~T}$ when they are equipped with power and pillars of power and are fully compatible with the system of viewing per night time. 


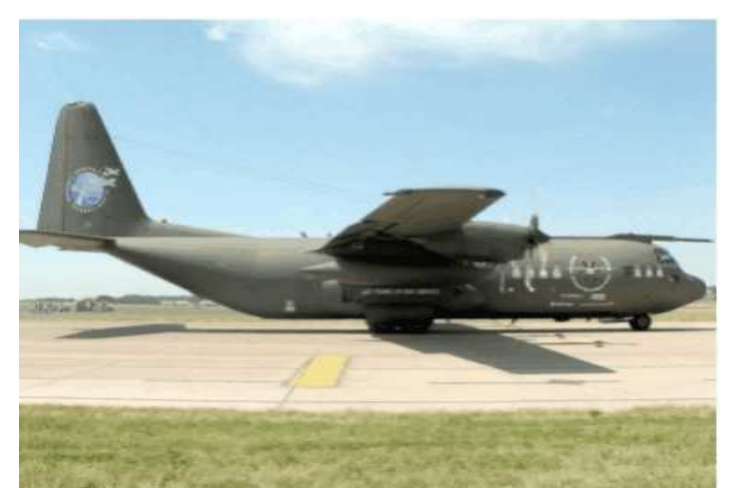

Fig. 6. Royal air force C-130K (C.3) Source: https://en.wikipedia.org/wiki/Lockheed_C130_Hercules\#/media/File:Raf.hercules.c130k.c3.arp.jpg

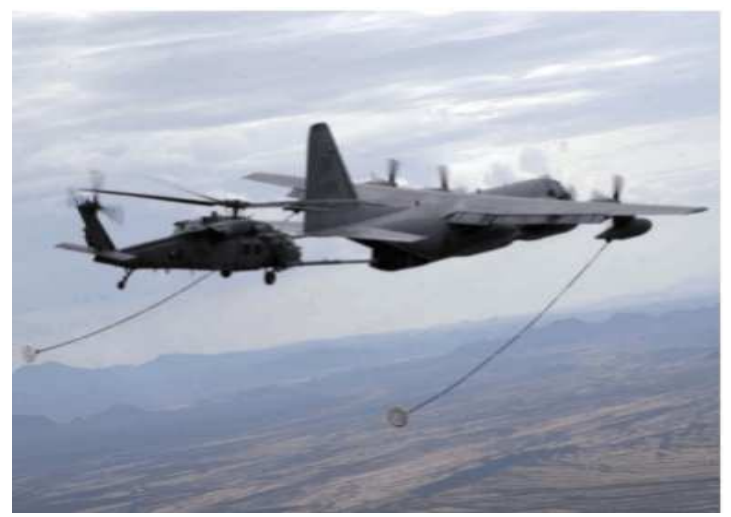

Fig. 7. USAF HC-130P refuels a HH-60G Pavehawk helicopter Source: https://en.wikipedia.org/wiki/Lockheed_C130_Hercules\#/media/File:HC-130P-N_refuels_HH60G.jpg

$\mathrm{RC}-130$ is a version of the recognition. A single example is used by the air forces of the Islamic Republic of Iran, plane being initially sold the former air forces of the imperial Iranian.

Lockheed L-100 (L)-382 is a variant civil society, equivalent to a model $\mathrm{C}-130 \mathrm{E}$ without military equipment. L-100 also has two versions.

In the '70s, Lockheed has proposed a variant C-130 with engines turbofan, rather than with the turbo prop, but the air force in the U.S. preferred the performance of the flight of the aircraft. In the $1980 \mathrm{~s}$, model C-130 was to be replaced with the project of the Advanced Medium COVEY Transport. The project was canceled and the C130 has remained in production.

Based on the lessons learned, Lockheed Martin amended a commercial variant of the model C-130 in a bed test of High Technology (HTTB). This aircraft for the testing of established recordings rapid information about the performance of the runways and the landing and extended in a significant way the data base for the future products derived from the model C-130.

The amendments made to the HTTB have included the helicopters enlargements of string, a long tiller agreements, dampers sides with quick-acting, an extension of the wing for the submission of the high wing, a rear wing higher fins and dorsal, the addition of three panels of spoiler to each of the systems of main drive and the landing of the longitudinal landing, as well as changes in the commands of the flight and a change from the mechanical links direct assisted by hydraulic stimulation at the controls of the fully powered, in which the mechanical connections to the command of the flight operates only hydraulic control valves on the corresponding amplification.

The first HTTB flew to 19 June 1984, with the civil registration of N130X. After demonstration of many new technologies, some of them being applied in the C-130J, HTTB has been lost in a fatal accident on 3 February 1993, at the base of the Dobbins Air Reserve Base from Marietta, Georgia.

The accident was assigned disengagement the control system of the flight by driving, which resulted in the total loss of the ability to control the tiller while performing the tests of the minimum speed control on the ground (Vmcg). Disengaging was the result of the inadequate design of the package of integrated actuator of the tiller, by the manufacturer or; review insufficiency of the safety of the system by the operator has not taken into account the consequences of inadequate design on all of the operation.

A factor which has contributed to the accident was the lack of flight crew incapacitation of training engineering test.

In the years 1990, improved model C-130J Super Hercules has been developed by Lockheed (later Lockheed Martin).

This model is the new version and the only model of the production. Outside the similar to the classic Hercules, model $\mathrm{J}$ is with turbo prop us, with the blade with six arms, digital avionics and other new systems.

Lockheed Martin C-130J Super Hercules is an aircraft military transport turbo-prop with four motors. $\mathrm{C}-130 \mathrm{~J}$ is a complete upgrade of the Lockheed Hercules C-130, with new engines, underbody of flight and other systems. Hercules family has the longest continuous production of any military aircraft in history. In those over 60 years of activity, family has participated in the military operations, civil and humanitarian operations.

Hercules has exceeded several plans as an argument envisaged, in particular the competitors of the Advanced Medium COVEY Transport.

Fifteen nations have placed orders for a total of $300 \mathrm{C}-130 \mathrm{~J}$, of which 250 aircraft have been delivered from the month of February 2012 (Fig. 8). 
$\mathrm{C}-130 \mathrm{~J}$ is the new version of the model Hercules and the only model still in production. Outside similar to that of the classic Hercules, in general appearance, model $\mathbf{J}$ has an up to date technology considerably. These differences include the new engines turbo prop RollsRoyce AE 2100 D3 with composite helicopters Dowty R391, the jet digital (including displays for the Head of Driving (HUD) for each pilot and less stringent requirements of the crew. These changes have improved performance over its predecessors $130 \mathrm{C} \mathrm{E} / \mathrm{H}$, such as a $40 \%$ higher, a maximum speed of $21 \%$ higher and a distance of the flight less than $41 \%$. The model $\mathrm{J}$ is available in a standard-long or stretched -30 . That by cargo plane and the aircraft, his crew C-130J includes two pilots and a carrier to the load (without navigator or engineer of flight), while specialized variants of USAF (e.g., AC-130J, EC-130J, MC-130J, HC-130J, WC 130J) can have crews larger, such as seafarers/liaison officers of the systems of fight or other officers and crew members of airplanes.

The body of the American marine KC-130J uses the head of a crew for operations conduct more expeditionary warfare should. The merchandise of C$130 \mathrm{~J}$ is a height of $12.5 \mathrm{~m}$, height of $2.74 \mathrm{~m}$ and width of $3.05 \mathrm{~m}$ and loading is carried out from behind the catching. The aircraft can also be configured with the "system for the handling of the load to be improved". The system is composed of one base station the computerized charging, from which the user can remotely control the winch under the floor and can also configure the flip-floor to manipulate the loads with pallets or the floor.

First developed for USAF, this system allows rapid change in the roles and thus extends the time available of C-130J for job completion.

Lockheed Martin received the order to launch for the model J from RAF, who ordered 25 airplanes, first deliveries starting with 1999 that Hercules C4 (C-130J-30) and Hercules C5 (C-130J). The standard C-130J has had a cost of flight in the amount of 62 million dollars in 2008.

In mid-June 2008, the United States Air Force have been awarded a contract of 470 million dollars in the company Lockheed Martin for six aircraft KC-130J altered to be used by the forces of the air and the command of special operations. The contract has led to the variants $\mathrm{C}-130 \mathrm{~J}$ which will replace the aging of the HC-130 and MC-130. The combination of the HC-130J Combat King II has carried out the tests of development on 14 March 2011. The end point of the test facility has been replenish the air-air and was the first refuelling boom with a $\mathrm{C}-130$, in which the receiver fuel supply has been installed the production of aircraft. This test procedure has been applied and for the plane MC-130J Combat Shadow II in production for the command of special operations for the forces of the airline (Fig. 9).

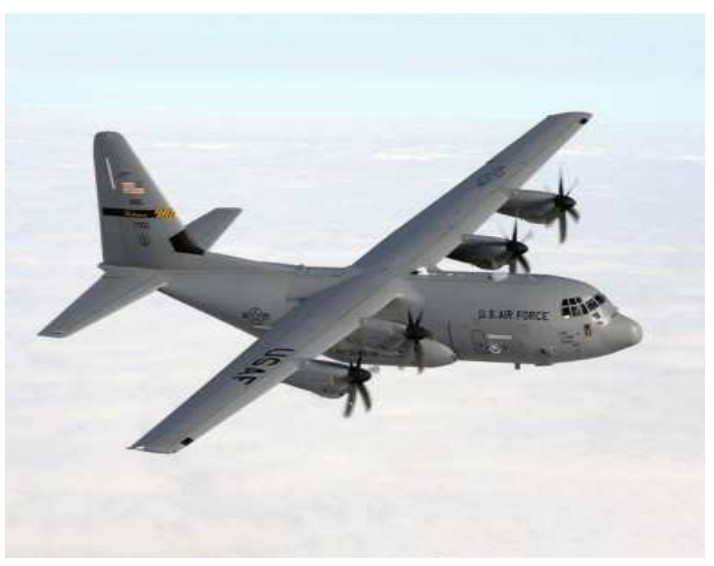

Fig. 8. A U.S. Air Force Lockheed Martin C-130J Hercules aircraft

Source: https://en.wikipedia.org/wiki/Lockheed_Martin_C130J_Super_Hercules\#/media/File:C130J_135th_AS_Maryland_ANG_in_flight.jpg

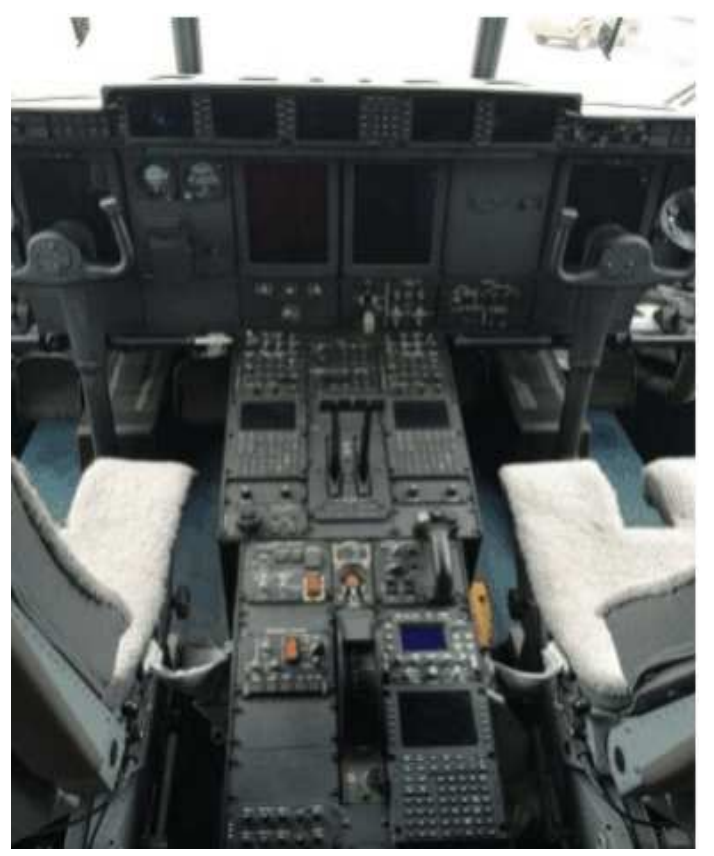

Fig. 9. Super Hercules cockpit Source: https://en.wikipedia.org/wiki/Lockheed_Martin_C130J_Super_Hercules\#/media/File:CC130J_Hercule Cockpit.JPG

With the addition of kit of missions ISR/Weapon Mission Marine Corps, variant the tank KC-130J will be able to serve as an aircraft of survival and can provide fire the palm to the ground in the form of Hellfire missiles or Griffin, bombs with precise guidance and possibly $30 \mathrm{~mm}$ cannon of fire in an upgrade later. This capability, designated as "Harvest HAWK" (Hercules Airborne Weapons Kit), can be used in scenarios in which the accuracy is not a requirement, such as the 
denial of the area. The plane shall retain the original capacities in the refuelling and transport. The whole system can be disposed of in a day, if necessary (Fig. 10).

Super Hercules have been used on a large scale of USAF and USMC in Iraq and Afghanistan. Canada has also filed the plane CC-130J in Afghanistan.

$\mathrm{C}-130 \mathrm{~J}$ from several countries has been carried out in support of the operation the USA Odyssey Dawn and of the Operation Unified Fabric Protector of NATO during the civil war in the Libyan 2011.

Starting with the first flight of 5 April 1996 to 30 April 2013, 290 aircraft C-130J Super Hercules operated by 13 nations have exceeded 1 million $h$ of flight.

In January 2013, reported that some of the shipments C-130J of Canada have had microchips counterfeit Chinese in their displays in the pilot. These parts are more likely to fail and lead to a fault, such as instrumentation screens empty during the flight. An investigation of 14 months carried out by the Commission for the armed services of the US Senate has concluded that the counterfeit parts of Hercules and other military equipment are prone to failure with potential "calamitous consequences". The investigation in the US Congress showed that microchips false Hercules were originally made by the giant Korean Electronics Samsung in the '90s and more than a decade later, have been recycled, renovated and notified to seem authentic by a company in China. Samsung said later that "it is not possible to design the reliability of the parts" modified. The investigation the U.S. has reported that the problems encountered by Hercules have appeared for the first time in 2010, when the instrument panel has failed on an aircraft USAF during their work.

On 20 August 2013, the power of the Indian airline has been the highest landing a C-130J the gun Daulat Beg Oldi of Ladakh at a height of $1664 \mathrm{~m}$.

In October 2010, air forces have launched a request for information on the capabilities of the CRFI () for the development of new for the replacement of the C-130. The new aircraft has a load capacity of $190 \%$ higher and assumes the task of the vertical maneuver fitted (MVM). The highest payload and the mission will enable it to carry the armored vehicles with the average weight and throwing them in places without gangs long. Are taken into account various options, including new models or improved with Fixed fenders, rotorcraft tiltrotors, or even a airship. The development might begin in 2014 and will become operational in 2024. The fleet C-130 of approximately 450 aircraft would be replaced with only 250 aircraft. Air forces have tried to replace the C-130 in the '70s by this project Advanced Medium COVEY Transport, which has led to the C-17 Globemaster III which replaced the C-141 Starlifter. The laboratory of research for the Air Forces financed the protesters Lockheed and Boeing concept Speed Agile, which was the achievement of an aircraft flock which can lift off and to land at speeds up to $70 \mathrm{~km}(130 \mathrm{~km} / \mathrm{h}), 81 \mathrm{mph})$ more than $2000 \mathrm{ft}(610 \mathrm{~m})$ and the cruise to Mach 0.8plus. The design of Boeing used the upper surface blowers engines embedded on the inner wing and blown flaps for the control of the traffic on the outer wing. The project to Lockheed used also plugged flaps, but inside their have been used the ejector nozzles reverse proprietary. The design of Boeing has completed over $2,000 \mathrm{~h}$ of tests for wind tunnel at the end of the year 2009. It has been a model of $5 \%$ of the design of a narrow body with a load capacity of 55,000 lb $(25,000$ $\mathrm{kg}$ ). When the model AFRL has increased payload at $29,000 \mathrm{~kg}$, has tested a model of $5 \%$ on a large scale, with a total weight of take-off $303.000 \mathrm{lb}(137.000 \mathrm{~kg})$ and a dimension "A400M" 158 in $(4.0 \mathrm{~m})$ range of goods. It would be powered by four turbines IAE V2533. In August 2011, AFRL launched the images demonstrator concept Lockheed Agile Speed. A model with the ladder of $23 \%$ has passed through the tunnel tests the wind to demonstrate the elevator supplied with a hybrid that combines a structure of the airline with low traction and a mechanical assembly easy to reduce the weight and a streamlined better. The model has had four engines, including two turbofan Williams FJ44. The date of 26 March 2013, Boeing has received a patent for the aircraft with the actuator with wings with drawbar.

Starting with January 2014, the command for the mobility of the airline, the command for the air force and a laboratory of research for the air forces are located in the incipient phase of defining the requirements for the Clix program of the next generation to replace both $\mathrm{C}$ 130 and C-17. An aircraft were produced from the beginning of the years 2030 until in the years 2040 .

If it decided to act in the air space in question, the acquisition of the air forces from $\mathrm{C}-130$ will end up at the end of the decade, so as not to be able to operate until in the years 2030 and which should operate when may not operate in this environment.

The development of the airline depended to a large extent on the "plans manual tactical and operational" of the Army. Two different planes of goods might be created in order to carry out separately from tactical missions and strategic, but that course which should be continued to be decided in advance that the $\mathrm{C}-17$ to be withdrawn.

Lockheed Martin Missiles and Control wires (LM MFC) is a business unit Lockheed Martin with headquarters in suburbia of Dallas, Grand Prairie, Texas.

The arsenal of offensive and part of the unit includes the rockets air-to-air and air-ground, naval missiles and rockets, control systems of the fire and sensors, systems for the support of the fire, dart throwers the missile defense systems and Nato is enforcing a UN resolution... antitank guns. In 2012, the unit has been the recipient of the Malcolm Baldrige National Quality Award. 


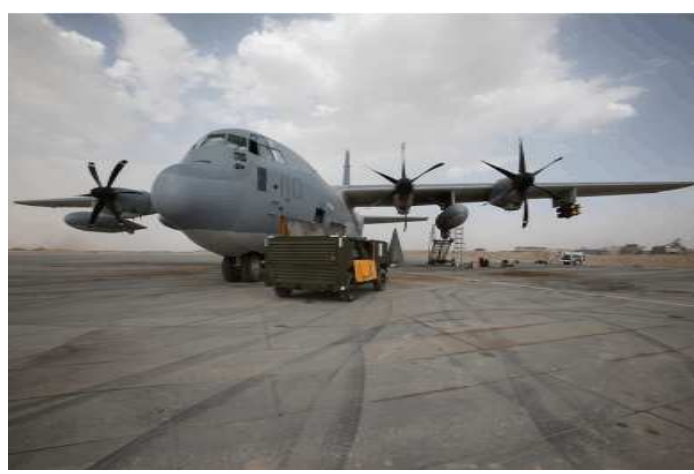

Fig. 10. A KC-130J showing the AN/AAQ-30 Targeting Sight and AGM-114 Hellfires on the left wing in Afghanistan, 2011 Source: https://en.wikipedia.org/wiki/Lockheed Martin_C130J_Super_Hercules\#/media/File:KC130J_Harvest_Hawk_(front)_at_Camp_Dwyer_Afghani stan_2011.JPG

LM MFC has approximately 10,600 employees, most of them being divided between Orlando, Florida and Grand Prairie, Texas. Other major facilities LM MFC are located in Archbald, Pennsylvania; Chelmsford Crown, Massachusetts; East Camden, Arkansas; Horizon City, Texas; Lufkin, Texas; Ocala, Florida; Santa Barbara, California; Troy, Alabama and Ampthill Bedfordshire (a portion of the Lockheed Martin UK), (Fig. 11).

\section{Lockheed Martin F-35 Lightning II}

Lockheed Martin F-35 Lightning II is a family of hero with one place, with one place, with multiple sealing (Fig. 12).

The aircraft combat of fifth generation is designed to carry out the attack at ground and air defense. It has three main models: variant the conventional Takeoff and landing F-35A, variant F-35B with Short Takeoff and Land Vertically (STOVL), as well as the barrier to assist Catapult assisted by carriers F-35C was Arrested by the Recovery (CATOBAR). On 31 July 2015, Seamen of the United States have declared ready for the conduct of the first escadre of combatants F-35B after intensive testing.

On 2 August 2016, the forces of the airlines in the U.S. have declared the first team of warriors F35 prepare for battle.

F-35 lowers of X-35, the winning project program of the Joint Strike Fighter (JSF).

A team of industry aerospace, led by Lockheed Martin, has designed a si produce it. Other Partners the major industry F-35 include Northrop Grumman, Pratt \& Whitney and BAE Systems.

The first F-35 flew to December 15, 2006. USA intends to buy 2.457 of aircraft. The variants are to provide the greater part of the air forces the tactical fitted with air forces the U.S. Navy and Marine Corps in the coming decades. Deliveries F-35 for the American army is scheduled up to the 2037 gymnasium, with a long life designed by 2070 .

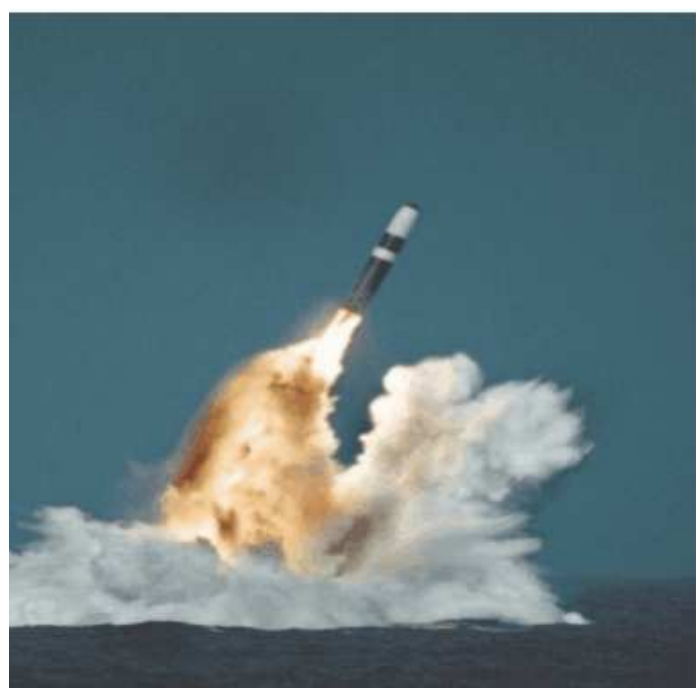

Fig. 11. Submarine launch of a Lockheed trident missile Source:

https://en.wikipedia.org/wiki/Lockheed_Martin\#/medi a/File:Trident_II_missile_image.jpg

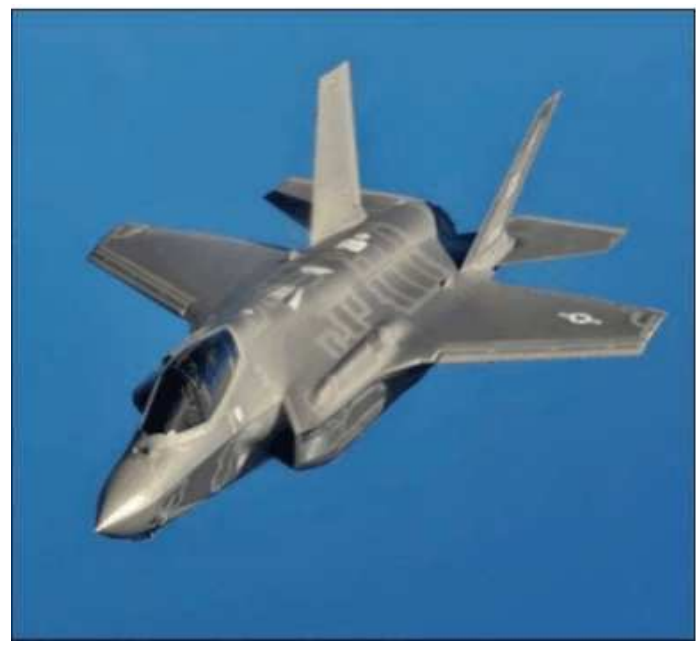

Fig. 12. F-35A Lightning II Source: https://en.wikipedia.org/wiki/Lockheed_Martin_F35 Lightning_II\#/media/File:F-

$35 \bar{A} \_$flight_(cropped).jpg

The United States financed mainly to the development of the F-35 JSF, with additional financing from partners. Partner countries are either NATO member states, be close allies of the USA.

The United Kingdom, Italy, Australia, Canada, Norway, Denmark, the Netherlands and Turkey form part of the program for active; several other countries have ordered or intends to control the F-35.

The program is the most expensive military system military equipment from the history and was much criticized inside and outside the government in the US and in allied countries. 
Critics argue that the plane is affected by the faults of the design", many of them are accusing the acquisition process in which Lockheed was allowed to develop, to test and to produce at the same time F-35 instead of ... faults before the burning of the production line. "Until 2014 the program has been"163 billion dollars over budget "and seven years ago"critics argue that the low costs of the program and the political pace make it "too large to kill" (Lockheed Martin F-35 Lightning II, From Wikipedia).

\section{Lockheed C-141 Starlifter}

Lockheed C-141 Starlifter (Fig. 13) has been an airplane military strategic used in strategic goal in the service of the blowing air Mobility (Mab) of the United States Air Forces (USAF). The aircraft has been used also by AMC with fenders airline and with wings of mobility airline of the blowing up of the Air Forces (AFRC) and Air National Guard (ANG) and in subsequent years that wing of mobility the blowing up Education and Training (AETC) dedicated training C141, C-5, C-17 and KC-135.

Initially submitted to replace the aircraft with the load with pistons smaller, such as C-124 Globemaster II, the $\mathrm{C}-141$ has been designed for the requirements laid down in 1960 and flew for the first time in 1963. Deliveries of production of an airplane 285 started in 1965: For US Force and for the National Administration Aeronautics and Spatial (NAS) to be used as an observer. The aircraft Lockheed C-141 Starlifter has been used for more than 40 years ago because the capabilities of the upper her in the field could not be matched by other models for a very long time, until the USAF has withdrawn the last C-141-changer from the service in 2006, after having replaced airlifter C-141 with upper airplanes C-17 Globemaster III.

At the beginning of the years 1960, military service in the air transport of the air forces of the United States of America (MATS) was based on a significant number of aircraft with the power train strategic air transport. Taking into consideration that these aircraft were for the most part tiresome models and air force needed the benefits of power of reaction, USAF ordered 48 Boeing C-135 Stratolifters as an interim step. C-135 has represented a stop point useful, but he was only the loading door side and that the equipment at the bigger the oversize and could not be fitted neatly into, especially those used by the U.S. Army (Fig. 14) in the spring of 1960, the Air Force launched the operational requirement specifies 182 , asking for a new aircraft to be able to carry out both the strategic mission and tactical of carriage by air. Strategic role has requested that the aircraft to be able to carry out the tasks with a radius of at least $3500 \mathrm{nmi}(4000,6500 \mathrm{~km})$, with a load of over $27,000 \mathrm{~kg}$. The role of the nation has imposed that he or she is able to carry out flights and at low altitude and to carry paratroops into battle. Several companies replied to the lots 182, among which Boeing, Lockheed and General dynamics.

Lockheed replied to the requirements by a unique design model: Lockheed Model 300, the first great jet designed from the beginning for the carriage of goods. The 300 have a wing mounted high, with four motors turbofan TF33 21,000 lbf (93.4 kN), get caught beneath the wings.

An important aspect was the height of the cab floor only 1,27 $\mathrm{m}$ above the ground, which allows easy access into the cab through the rear doors. The two side doors from the rear have been designed to allow the aircraft to descend parachutists (in August 1965 the aircraft made the first margin of paratroopers from an aircraft with a jet of force). The doors of freight from the rear could be opened in flight to allow the air transport of goods.

The wings mounted on the shoulder they gave a inner distance in the luggage compartment of 10 feet $(3.05 \mathrm{~m})$ width, height of $9 \mathrm{ft}(2.74 \mathrm{~m})$ and length of $21 \mathrm{ft}(21,34 \mathrm{~m})$. The size of the allowed the Starlifter to transport, for example, a missile inquiring into organized intercontinental destination LGM-30 Minuteman completely in the container or (Fig. 15). The aircraft was able to carry up to $32.136 \mathrm{~kg}$ over short distances and up to $41.730 \mathrm{~kg}$ in the version configured for transporting Minuteman, who removed the other equipment. The aircraft could carry also up to 154 soldiers, 123 of paratroopers or 80 patients.

The first official act of President John F. Kennedy (after the inauguration) was to order the growth of Lockheed 300 on 13 March 1961, with a contract for five aircraft for testing and assessment which were to be designated C-141.

An unusual aspect of the aircraft was that has been designed to satisfy both the standards of military airworthiness and civil society. The concept of solution C-141A, the number 61-2775, has been manufactured and assembled in record time, being launched from the factory Lockheed from Marietta, Georgia, at 22 August 1963 and which has flown on 17 December, at the 60th anniversary of the first flight of the Wright Brothers.

The company and the air force have initiated then a testing program operational and delivery of 284 aircraft, initially by units mats, renamed later in 1966 in military command of the aircraft (MAC).

An effort to sell the aircraft to the civil market has led to the provisional order from the Flying Tiger Online and smooth path in Airways for four aircraft each.

These were to be a version of the lying down, with a length of $37 \mathrm{ft}(11,28 \mathrm{~m})$ longer than the C-141A and sold it SuperstarLifter-300. Other amendments were also included in order to make it more trade.

Its development but has not been financially supported the political-and this is the reason why it has been built only one demo aircraft civil society. For that it has made the trade sales, Lockheed has donated the aircraft of NASA. 


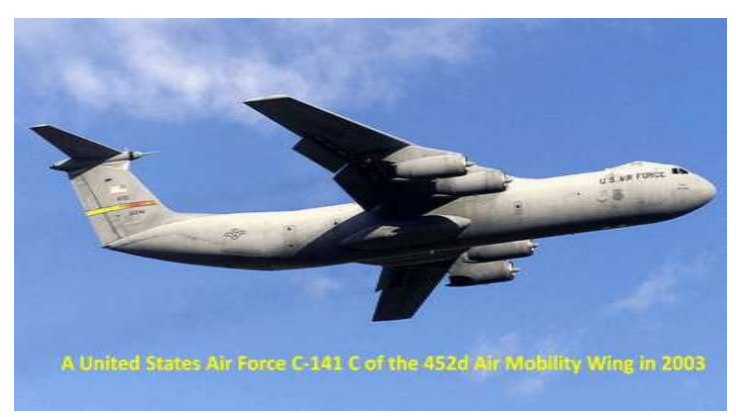

Fig. 13. Lockheed C-141 starlifter Source: Petrescu and Petrescu (2013a)

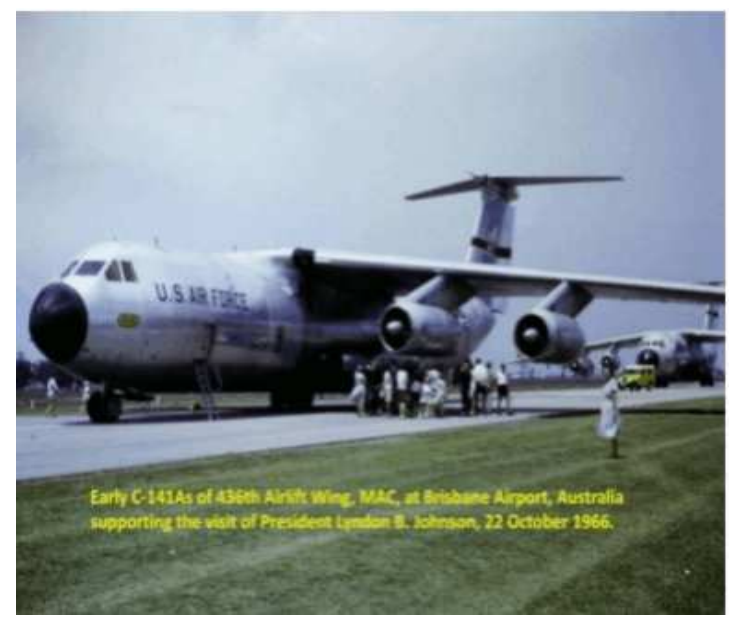

Fig. 14. Early Lockheed C-141 airlift wing Source: Petrescu and Petrescu (2013a)

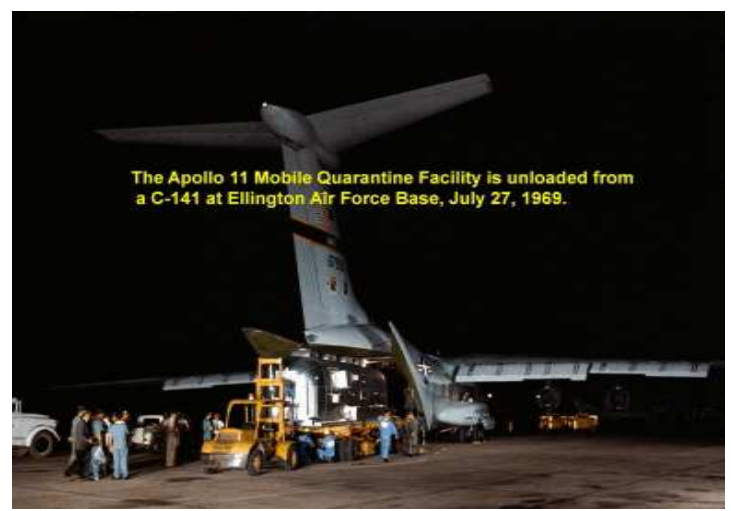

Fig. 15. Lockheed C-141 Airlift Wing for Apollo 11 Source: Petrescu and Petrescu (2013a)

The prototype and aircraft of development have started then a program intensive operational test, with the first delivery to the mats (63-8078), on 19 October 1964, 1707a Air Wing Heavy (Training), Tinker Air Force Base, Oklahoma.

Testing continued and on January 29, 1965 was granted a certificate of Federal Authority.

The initial delivery that took place by an operational unit (63-8088) has been made on April 23, 1965 for the acts such transport by air, 1501 century wing of air transport, Travis County Air Force Base, California. Although the operational test continued far more time, because of the involvement of the military of the United States in South Vietnam, C-141 was employed very quickly in the operational missions to fight because of the war in that period in which door promised political-military.

C-141 participated in the operation of the deep freezing.

The image in Fig. 16 was a personal artistic photo shot by Field Engineer flight C-141, Bob Pederson, in October 1997 . There was a moment rarely penguins he approached so much aircraft on gang of ice from McMurdo (Fig. 16).

All a photo artistic is and that with a model C-141 throwing colored vapor over the Antarctic (Fig. 17).

\section{Lockheed C-5 Galaxy}

The Galaxy Lockheed C-5 is a military aircraft of transport large built by Lockheed which provides the air forces of the United States of America (USAF), with a capacity of the strategic air transport with a capacity of strategic intercontinental destination, which can transporting loads exaggerated and oversized, including all goods certified with air. The Galaxy has many similarities with its predecessor or C-141 Starlifter and most recently C-17 Globemaster. C-5 it is among the biggest military aircraft in the world.

The Galaxy C-5 had a complicated development; exceedance significant cost savings and Lockheed has suffered financial difficulties significant. Shortly after the entry into service, have been discovered fractures of the wings more aircraft fleet and C-5 was limited in capacity up to perform work corrective action. C-5M Super Galaxy is a version of the much improved with new engines and avionics upgraded designed to and extend the life after 2040 .

The Galaxy C-5 was operated by USAF in 1969. In that period has been used to support the operations military bases in all major emergency situations, including in Vietnam, Iraq, Yugoslavia and Afghanistan; and in the support of the allies such as Israel during the war in Yom Kippur and NATO operations during the Gulf War. The model C-5 was also used to distribute humanitarian aid and aid in case of emergencies and to support the program US Space Shuttle led by NASA (Fig. 18-21).

\section{Lockheed F-117 Nighthawk}

Lockheed F-117 Nighthawk is an aircraft of attack against the ground with a place, with dual motors, operated previously by the United States Air Force (USAF; Fig. 22-23). 


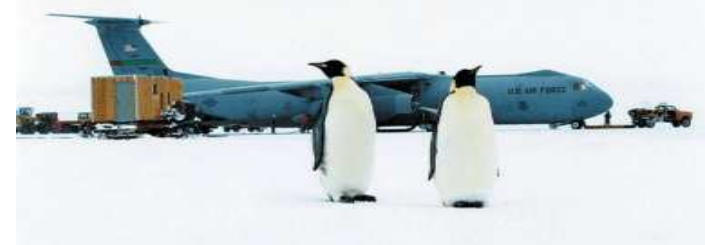

C-141 participating in Operation Deep Freeze

Fig. 16. C-141 who participate in the operation of the deep freezing Source: Petrescu and Petrescu (2013a)

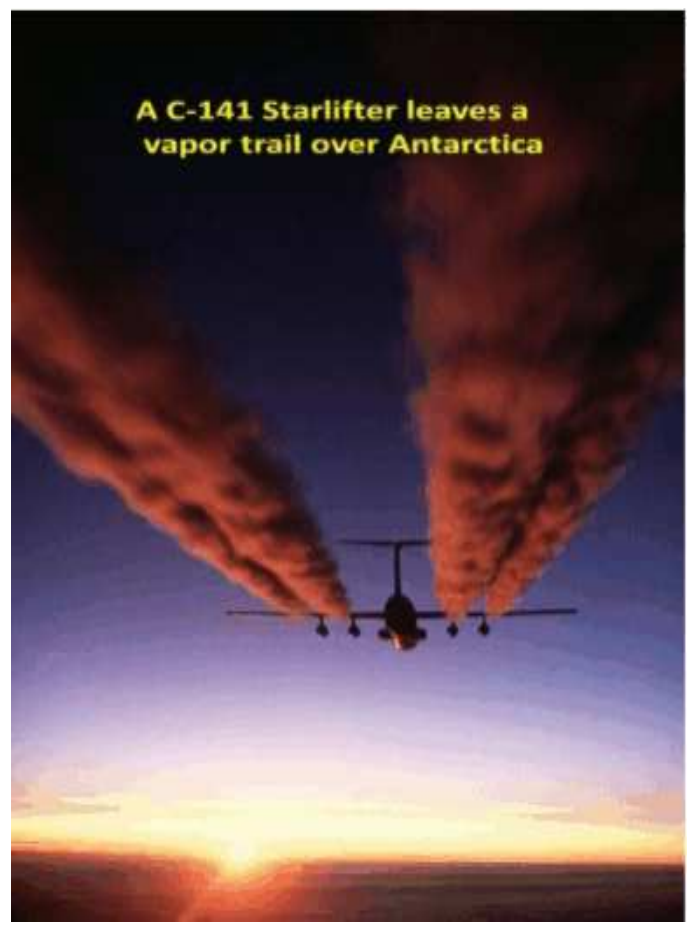

Fig. 17. A model C-141 throwing colored vapor over the Antarctic Source: Petrescu and Petrescu (2013a)

The first or flight has been in 1981 and has reached the status of the initial capability in October 1983. F-117 has been recognized and revealed to the world in November 1988.

A product of the Lockheed Skunk Works and a development of technology demonstratorului Have Blue, became the first operational aircraft originally designed around Stealth technology.

The F-117has been published on a large scale during the Gulf war from 1991.

It has been called in the usual way "Stealth fighter", though it was a plane of attack on the ground.

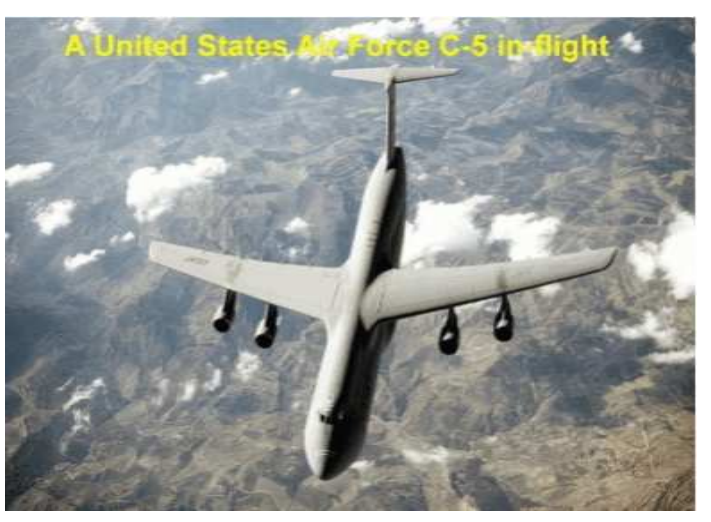

Fig. 18. A model Lockheed C-5 Galaxy Source: Petrescu and Petrescu (2013a)

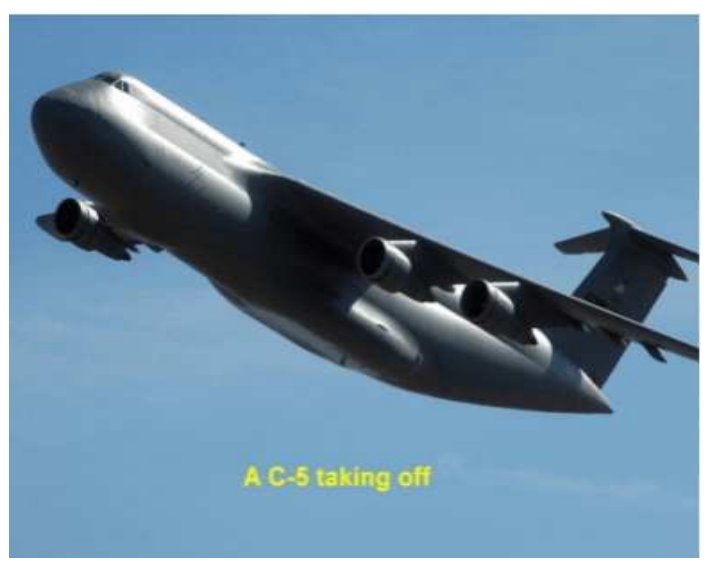

Fig. 19. A model Lockheed C-5 Galaxy taking off Source: Petrescu and Petrescu (2013a)

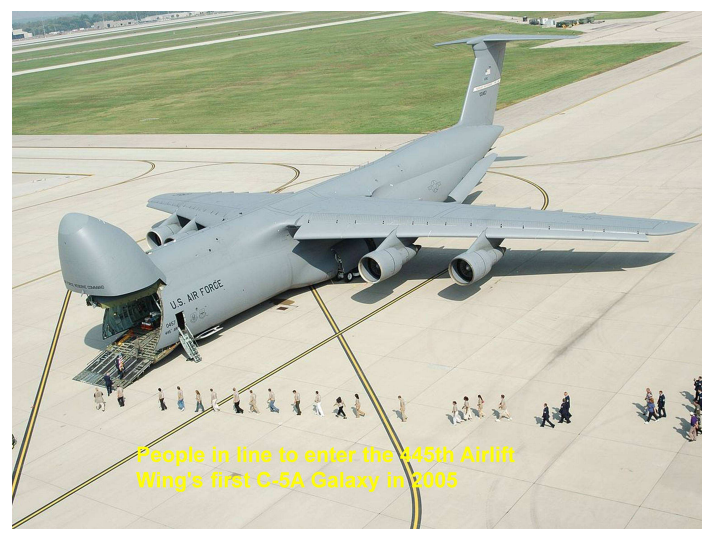

Fig. 20. People enter on a model Lockheed C-5 Galaxy, in 2005 Source: Petrescu and Petrescu (2013a)

The Air Force withdrew F-117 on 22 April 2008, in the first place due to the launching of the field F-22 Raptor and placing the imminent of F-35 Lightning II.

Have been built and sixty-four models F-117, out of which 59 have been versions of production with five prototypes. 


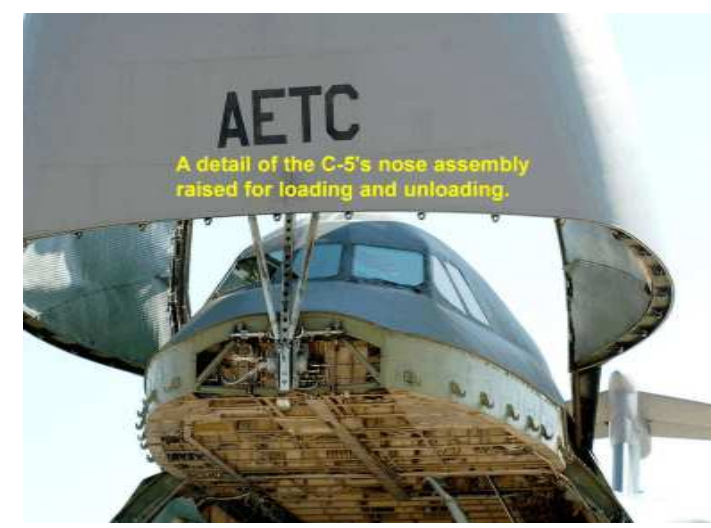

Fig. 21. The C-5's nose assembly raised for loading people Source: Petrescu and Petrescu (2013a)

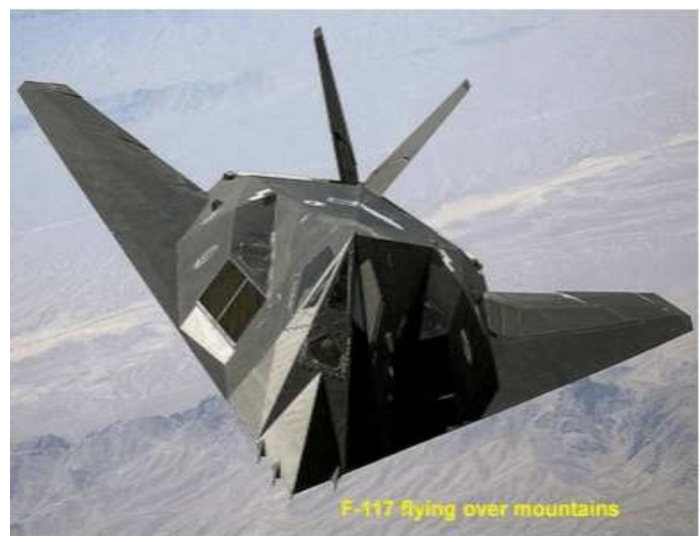

Fig. 22. Lockheed F-117 Nighthawk is an aircraft of attack against the ground with a place, with dual motors Source: Petrescu and Petrescu (2013a)

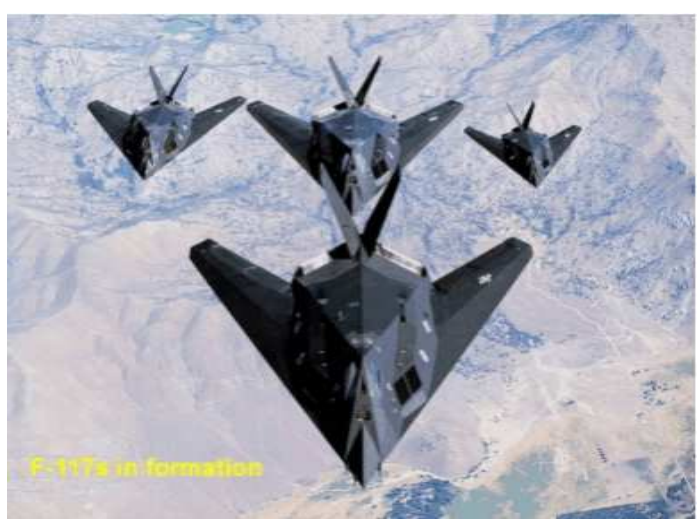

Fig. 23. Lockheed F-117s in formation Source: Petrescu and Petrescu (2013a)

\section{F-117N "Seahawk"}

At the beginning of the years '90, Lockheed has proposed an upgraded version, capable of transport, of F117, hereinafter referred to as "Seahawk" that the American brand as an alternative to the program A/F-X canceled. Unsolicited proposal has been received from the US Department of Defense, which has not had too many interest of the capacities of the mission the unique needs of such an aircraft, especially because it would take money from the Joint Advanced Strike Technology, which evolved in the Joint Strike Fighter.

The new aircraft would be differentiated by F-117 on several ways, including adding 'lifts, a poster, a wing less sharp and a queue reconfigured". The "N" would also be to use turbines General Electric F414 in place of the oldest from General Electric F404, in addition, the aircraft should be provided with the optional heavy points, allowing you to charge useful additional $3,600 \mathrm{~kg}$ and a new radar of attack against the ground with capacitate air-to-Air In this role, F-117N would be able to carry the rockets air-to-air AIM AMRAAM-120. After it had been rejected by the marina, Lockheed has submitted a proposal updated which included the capacity of post-combustion plants and a greater emphasis on F-117N as a plane multimission, rather than just an aircraft of attack. In their efforts to enhance the interest, Lockheed also suggested a version of land F-117B which shared the most of the capabilities of the F-117N. This option has been proposed to both the air forces of the USA, as well as the Air Forces Royal. This proposal renewed $\mathrm{F}-117 \mathrm{~N}$ has been known and that a/F117X. Neither the F-117N or F-117B have not been purchased by any of the parties (Fig. 24).

\section{Lockheed Martin F-22 Raptor}

Lockheed Martin/Boeing F-22 Raptor is a fight super-maneuverable, with a place, with dual motors fifth generation, which uses technology stealth. It has been designed primarily as fighter superiority of the air, but has additional capabilities that include attack on the ground, the electronic war and signals the roles of information. Lockheed Martin Aeronautics is the main contractor and is responsible for most systems of aircraft, the systems of armament and the final assembly of F-22. The Partner Program Boeing Defense, Space \& Security offer wings, the body of the rear, the integration of the avionics and training systems.

Plane has been named in a different way F-22 and F/A-22 in the years preceding the entry of the formal USAF service in December 2005 that F-22A. In spite of a period of prolonged development and expensive, The United States Air Force considers that F-22 is a critical component of the power of the tactical air in the United States and claims that the aircraft does not have no equivocation with any fighter known or designed.

Lockheed Martin claims that the combination of the Raptor stealth, speed, agility, the conscience of precision and situation, combined with the capabilities to fight the air-air and air-to-ground makes the best overall fighter in the world today. The great chief of the aircraft Angus Houston, former head of the Australian Defense, stated in 2004 as "F-22 will be the most remarkable aircraft to fight ever built" (Fig. 25). 


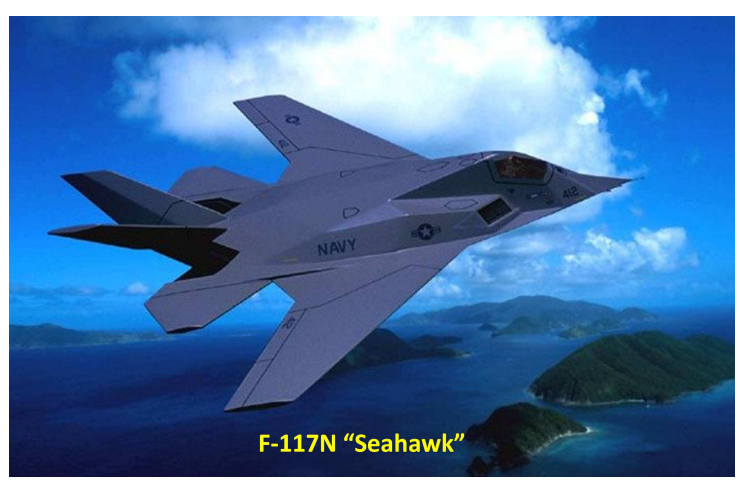

Fig. 24. F-117N “Seahawk” Source: Petrescu and Petrescu (2013a)

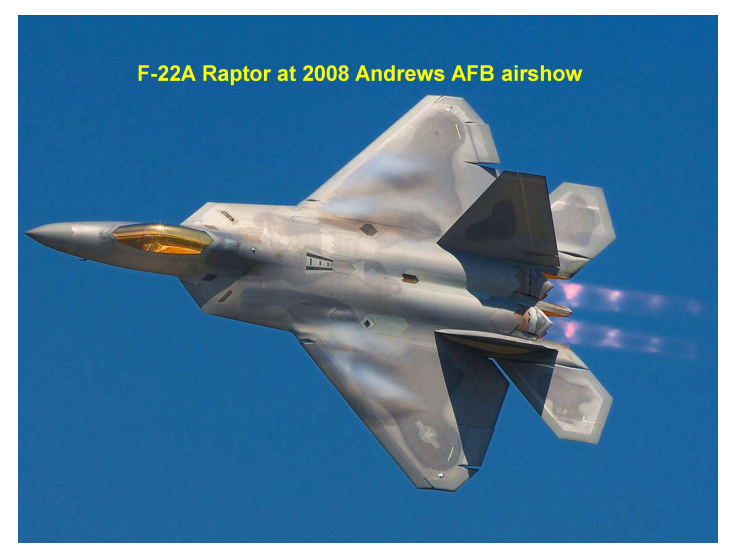

Fig. 25. Lockheed Martin/Boeing f-22 raptor is a fight supermaneuverable Source: Petrescu and Petrescu (2013a)

\section{Lockheed P-3 Orion}

Lockheed P-3 Orion is an aircraft with four motors turbo prop anti-submarine and maritime surveillance developed for the Merchant Navy of the United States and entered in the 1960s. To Lockheed based on commercial plane L-188 Electra. The aircraft is easily recognizable by switching the distinguishing mark of the queue or "Mad Boom", used for the detection of magnetic submarines.

Over the years, a plane has been many developments in design, especially in the case of packages its electronics. P-3 Orion is still used by many ships and air forces from all over the world in the first place for the maritime patrols, recognition, war anti-surface and war anti-submarine. They were built in total 734 P-3 and by 2012 will join several military aircraft such as Boeing B52 Stratofortress, who served 50 years of continuous use with the customer initial, in this case, the United States of America. The third plane P-3C of the American ship will be finally replaced by Boeing P-8A Poseidon (Fig. 26).

\section{Lockheed S-3 Viking}

Viking Lockheed S-3 is a plane with four places, which has been used by the US titles in order to identify and pursue the enemy submarines.

At the end of the 1990s, S mission-3B has moved to the war of the surface and to replenish the airline.

Viking has provided the capacities also electronic war and supervisory bodies of the surface for the group of the fight of the carrier. An aircraft based on carriers, climbing, with long action, with systems of automatic guns and capable of missions expanded with the recharge during the flight. Due to the low sound of the motors, has been dubbed the "Hoover" after a vacuum cleaner.

S-3 was withdrawn from the front fleet on board vessels bases in January 2009, missions being taken up the other platforms as well as the P-3Orion C, SH-60 Seahawk and F/A-18E/F Super Hornet. A few examples continue to be flying to test the air and helicopter squadron assessment THREE ZERO (VX-30) at the Naval Base Ventura County/NAS Point Mugu, California to operations for checking interval and the surveillance operations on the NAVAIR range Point Mugu and a single example is operated by the National Administration of aviation and spatial (NASA) at the Research Center Glenn of NASA (Fig. 27).

\section{Lockheed $U-2$}

Lockheed U-2, called "Dragon Lady" is an aircraft for the recognition with single motor, high altitude, operated by the United States Air Force (USAF) and which has been previously flying by the Agency Central Information (CIA). It offers the collection of information day and night, very high $(70,000$ footwell $/ 21,000 \mathrm{~m}$ ), with all of the meteorological information. The aircraft is used for research and development of electronic sensors, calibration of satellite and validation of data via satellite.

U-2 appeared prominent in several events during the Cold War, in the early stages the U-2s exceed usually the Soviet Union, the People's Republic of China, North Vietnam and Cuba. On 1 May 1960, the pilot of the CIA, Gary Powers, was shot while flying in the U-2 over the territory of the Soviet empire. During the Cuban missile on 27 October 1962, a U-2 controlled by major Rudolf Anderson, Jr, was shot by Cuba with two rockets surface facing toward TO-2 (Fig. 28).

\section{Lockheed Martin Supersonic Design Concept}

This future concept of the design of aircraft for the flight supersonic on earth comes from the team led by Lockheed Martin Corporation.

The simulation of the team shows the ability to obtain the flight on land by the sharp drop in the level of sonic arms through the use of a configuration with the engine "reversed-V'.

Other revolutionary technologies help to achieve the aims, the tasks useful and of environmental objectives. 


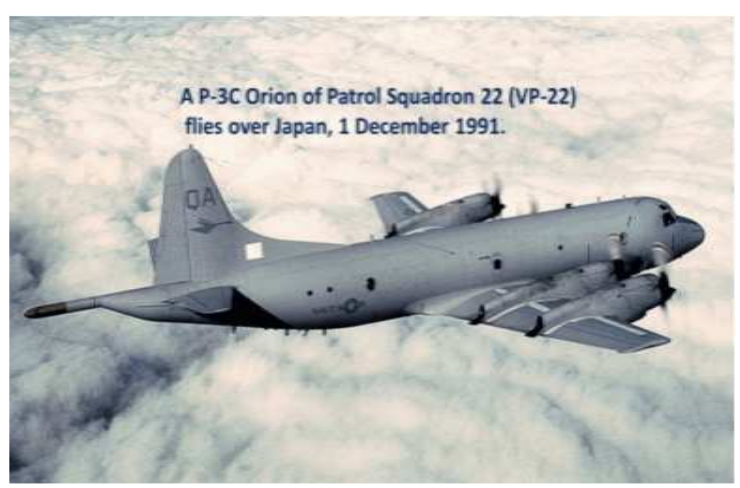

Fig. 26. Lockheed P-3 Orion is an aircraft with four motors turbo prop anti-submarine and maritime surveillance developed for the Merchant Navy of the United States Source: Petrescu and Petrescu (2013a)

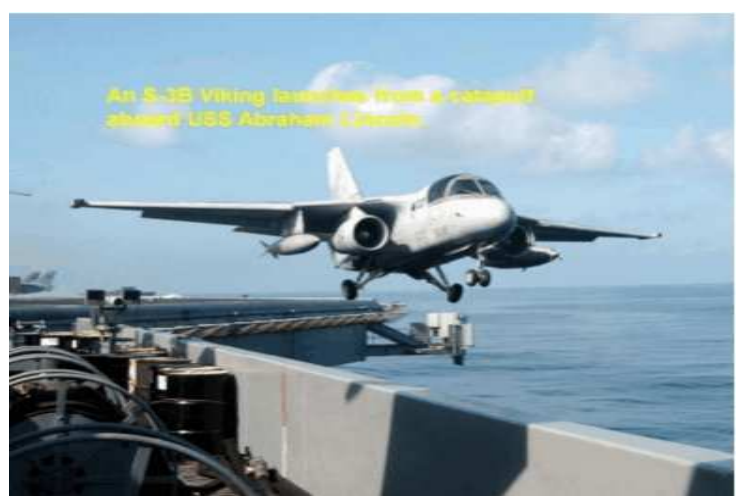

Fig. 27. Lockheed S-3 Viking is a plane with four places, which has been used by the US titles in order to identify and pursue the enemy submarines Source: Petrescu and Petrescu (2013a)

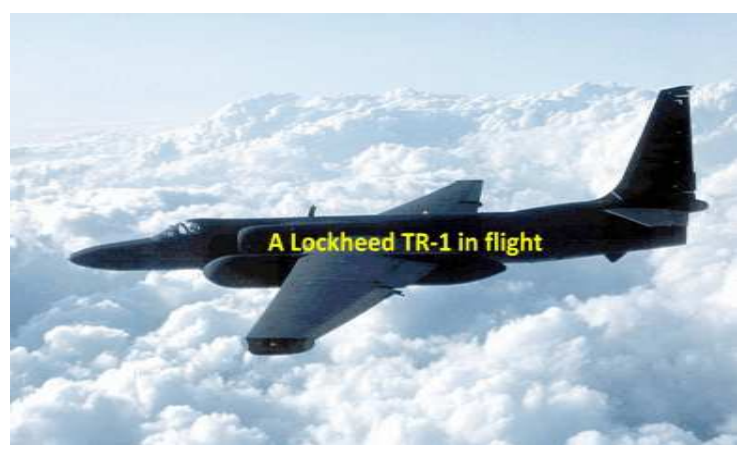

Fig. 28. Lockheed U-2, called "Dragon Lady" is an aircraft for the recognition, high altitude, operated by the United States Air Force (USAF) Source: Petrescu and Petrescu (2013a)

This concept of supersonic cruise is among the projects submitted in April 2010 to the direction of the Aeronautics Research NASA to NASA studies research funded in the field of advanced aircraft that could come into service in the 2030-2035 period (Fig. 29).

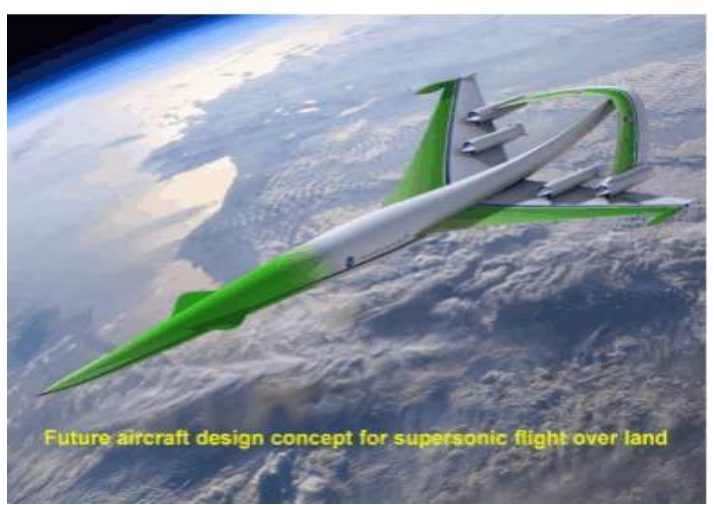

Fig. 29. Lockheed martin supersonic design concept Source: Petrescu and Petrescu (2013a)

\section{Results}

Lockheed Martin Advanced Technology Laboratories (ATL) is a department of Lockheed Martin, located in Cherry Hill, New Jersey, with approximately 220 employees. Other locations include Westlake Village, California, Atlanta, Georgia and Arlington, Virginia. ATL specializes in advanced research and development and is analogous to the Lockheed Martin Aeronautics division's famous Skunk Works.

The laboratories Advanced Technology (ATL) is at the forefront of the efforts of applied research and development of Lockheed Martin. Aligned with the director of the Technology Corporation, working for the advancement of scientific discovery and of the transition of technology in the area have risen, of the science of materials, of robotization and of the autonomy of systems of the spectrum, analysis of data and many others.

We enrich the diversity of thinking, working with some of the best and most brilliant of the government, industry and the academic environment. Our partners mayors of research include the agency for advanced research in the field of Defense (DARPA), governmental laboratories in the USA, universities and colleges Lockheed Martin from the Skunk Works ${ }^{\circledR}$, the center of advanced technology and many others.

We look much to the technology of the future transformation that will redefine the global security and although not know exactly what will change the world still, you probably already working on it.

Lockheed Martin Advanced Technology Laboratories has been on the first line of the research and development applied for almost a century. Our origins dating back in 1929, when a group of GE engineers have joined the RCA to develop the technology of television and work on the recording sound for cinematographic films. Known later as a group of advanced development, this has formed the core of the laboratories of advanced technology today.

Our heritage includes pioneering television 
fundamentals of the years 1930 and $1940 \ldots$ the creation of technologies of registration and laser for the program of the American space in the years 1950 and $1960 \ldots$ to advancing the voice recognition and scanning the bar code in the years 1970 and $1980 \ldots$ to activate the dialog between man and the computer and systems without pilot projects in 1990 and 2000.

We have over 80 years on the first line of the research and development applied, starting from the foundations of the television of the years 1930 and 1940, to create today architectures polymorphic computing and technologies for standalone systems without pilot. We have a legacy of the cultivation of the technologies that make possible to some of the most sophisticated systems in the entire world. We are a resource unrivalled advanced technology of calculation and demonstrations in the software development and the transitional period.

The 1980 we have pointing toward the robotics and artificial intelligence, combining the previous work the sensors, processors compact high speed and computers distributed. Our contracts with the electronic mail service in the U.S. have produced the vision of machinery for sorting parcels and a mechanical system which has manipulated and sorting correspondence with the forms to be unusual. In the meantime, in artificial intelligence, we have focused on the expert systems and data of the merger by the essence of the computers to imitate the deductive processes of the human mind. We have created expert systems for US Titles which increased the effectiveness of the maintenance of the airplane and that faults diagnosed in the AEGIS combat system-command and control of the ship to the USA on board of the most modern crushers. Other works during this period have included the recording of data which have been recorded by the Record/Playback of more than 10 billion bit/second. Our circuits the large scale integration and the circuits high-speed, developed using metal semiconductor company with additional oxidation, allowed 200,000 transistors per unit with the delays of the gates in the region of sub-nanosecond. Our activity for the Supply Agency of the projects of advanced research has produced a math coprocessor with instructions reduced, capable of 50 million instructions/second.

\section{0}

We have developed a technology that imitates the software of the human brain so complicated that absorb and coalesces in just a few seconds for the volumes of data from the numerous entries in an assessment almost in real time to a situation. We have achieved this by the use of technology on the fusion of data and the software agent mobile intelligent on programs such as The Association of the pilot Rotorcraft to the Army U.S. and the demonstration of the common technological advanced DARPA. We have developed programs that allow a person to talk with a computer while he was in the heat, to question the data bases on the and battlefield and to answer in a few seconds of applications. We have achieved this by combining the understanding of spoken language and agents mobile intelligent the program Listen, communicated, Show-for the DARPA.

\section{The years 2000}

Imagine a team of helicopters and airplanes without crew that work together as a team despite the fact that the lines of communication are not reliable. This is the reality due to the work which I have done it in the autonomy of the automatic transmission and the assessment of the situation. We have developed a life cycle of the software on the basis of agents to accelerate the transition of the autonomous capabilities and intelligent in military systems are to be used. Imagine a computer system that acts as an assistant human consumption. This not only that it meets the tasks through speech recognition - understand normal models of speech in the specific context. I used the agents of software to communicate between people and applications, thus making it easier to find and communicating information.

\section{0 and Beyond}

Keeping our customers in safety and well-informed, we focus on providing creative solutions and innovative for the problems of the most difficult of our customers in the cyber security, computer and advanced analysis, material science, human systems, robotics and the management of the spectrum. Combine the interests of customers to develop a solution that would make the best use of technology, taking into account the constraints of the real world. Also, we focus on the perception of machinery and views on the computer, science cognitive and Neurosciences had worked in applications, nanotechnologies and science of materials, social science and communicating abilities quantum calculation.

We made an interesting activity for over 80 years and we intend to continue the heritage of the technological successes in the future.

\section{Discussion}

The agency for projects of advanced research in the field of Defense (DARPA) sponsors an event with a round table in the field of scientific research, with a community greater range of performing artists in higher education, in order to bind its members in a dialog on the opportunities of technology and research.

The event will include the discussion of the vision and objectives of the Agency, overview of each technical office of DARPA through the management of the office and an explanation of the mechanisms of working with DARPA. 
In the next three years, the Office of technology of the Microsystems of DARPA will organize a series of events which are competitive as the next great challenge of the Agency-Spectrum Collaboration Challenge $\left(\mathrm{SC}_{2}\right)$ - which is in progress. $\mathrm{SC}_{2}$ is the first or the contest of cooperation in the field of automatic learning to overcome the scarcity of the spectrum of radio frequencies.

Today, access to spectrum is managed by its division in strips rigid, licensed only.

This process based on the man not adapts to the dynamics of the supply and demand and so cannot exploit the full potential capacity of the spectrum. In $\mathrm{SC}_{2}$, competitors will reimagini a new paradigm wireless more efficient in which the radio networks autonomous works to determine the dynamic mode the manner in which the spectrum can be used in a manner that is more effective from the moment in time.

The teams $\mathrm{SC}_{2}$ will develop this capacity discovery by taking advantage of the latest Artificial Intelligence (AI) and learning in the car and sophistication extended radios defined via the software. Finally, this competition aims not only to challenge the oscilloscope innovators from the academic environment and business to produce progress in collaborative you, but to catalysis a new paradigm of spectrum that can help to launch an age of abundance spectrum.

As a result of the preliminary competitions at the end of the year 2017 and the end of the year 2018, the finalists will compete in December 2019 for cash prizes amounting to 3.75 million dollars and, more important, in order to prove that have drawn up not the best framework of cooperation in order to ensure that the spectrum will be able to accommodate everincrease demand for ao use.

The challenge for the cooperation in the field of the frequency spectrum DARPA $\left(\mathrm{SC}_{2}\right)$ is the first competition of learning of machinery in collaboration in order to overcome the scarcity of the spectrum of the Radio Frequency (RF).

Today, the spectrum is managed through its division in strips rigid, licensed only. This process based on the man not adapts to the dynamism of the supply of and demand and therefore cannot exploit the full potential capacity of the spectrum. In $\mathrm{SC}_{2}$, competitors will display a new paradigm wireless more effective, in which the radio networks works in standalone mode to determine the dynamic mode the manner in which the spectrum should be used from time to time.

Our team has the radio design performs the most reliable successful communication in the presence of other competing radios could earn up to $\$ 3.500 .000$.

\section{Conclusion}

Lockheed Martin is a company aerospace global American, defense, security and advanced technologies with interests in the world. It has been formed by the merger of Lockheed with Martin Marietta in March 1995. Has its head office in Bethesda, Maryland, in the area of Washington DC. Lockheed Martin has 126,000 employees in the entire world. Marillyn Hewson is the current President and Chief Executive Officer.

Lockheed Martin operates in five segments of activity: Aeronautics, information systems and global solutions, missiles and control systems of the fire, rotating systems and the mission and space-based systems. The company received six times Collier County Trophy, including in 2001 in order to be part of the development of the propulsion system X-35/F-35B LiftFan and most recently in 2006 to lead the team that has developed the plane to fight F-22 Raptor. Lockheed Martin is currently developing F-35 Lightning II and lead the international chain of supply, leads the team for the development and implementation of technology solutions for the new SpaceFence (replacement AFSSS USAF) and is the main contractor for the development of the control module (Orion spaceship). The company invests also in the systems of health systems, renewable energy, intelligent distribution of energy and nuclear fusion compact.

On the date of 22 April 1996, Lockheed Martin has completed the purchase of firms from Corporation for the electronics industry of defense and systems of systems integration for the sum of 9.1 billion dollars, business being announced in January. The rest from his has become From Space and Communications. Lockheed Martin abandoned the plans for a fusion of 8.3 billion dollars with Northrop Grumman on 16 July 1998, because of the concerns of the government from the power of the potential of the new group; Lockheed/Northrop would have had control over $25 \%$ of the budget of the department for defense.

For Mars Climate Orbiter, Lockheed Martin has provided in incorrectly NASA with software which used the measurements in units of the usual force of the USA, when it was expected a value metric; this has led to the loss of Orbiter at a cost of 125 million dollars with the ship development of a cost 193,1 million dollars.

In May 2001, Lockheed Martin has sold Lockheed Martin Control Systems by BAE Systems. On 27 November 2000, Lockheed has concluded the sale of its activity of the electronic systems for aerospace by BAE Systems for 1.67 billion dollars, transaction announced in July 2000. This group has included Sanders Associates, Fairchild Systems and Lockheed Martin Space Electronics and Communications. In 2001, Lockheed Martin has won the contract for the construction of F-35 Lightning II; this was the greatest project of purchases of aircraft of the battle at F-16, with an initial 3,000 of aircraft. In 2001, Lockheed Martin has established a new investigation carried out by the office of the inspector general of the NASA, with the assistance of the Agency in respect of the audit of the 
contracts of defense. The company has paid to the Government of the United States the sum of 7.1 million dollars, based on the statements according to which its predecessor, Lockheed Engineering Science Corporation, claims submitted false statements concerning the rental costs by NASA.

In the date of 7 January 2013, Lockheed Martin Canada has announced that it will acquire the maintenance, repair and revision of the assets of the motor of the Aveo Performance Fleet Performance in Montreal, Canada.

\section{Acknowledgement}

We acknowledge and thank Mr Taher M. AbuLebdeh, Associate Prof at North Carolina A and T State Univesity, United States and Mr Muftah H. El-Naas PhD MCIC FICCE QAFCO Chair Professor in Chemical Process Engineering Gas Processing Center College of Engineering Qatar University and Ms Shweta Agarwala, Senior Research Scientist at Singapore Center for 3D Printing Nanyang Technological University Singapore for their suggestions and comments. The Authors acknowledge Liquid Metals Technologies Inc, Ca USAthat kindly supply the samples for the characterization and Dr Francesco Tatti (FEI Company Application Specialist SEM-SDB) for its contribut in the preparation of this paper experiments and analyses. The authors would like to appreciate the facilities and assistance provided by the Advanced Technology Dental Research Laboratory, Faculty of dentistry, King Abdul Aziz University. The authors would also appreciate the research technicians, Basim Al Turki and Fahad Al Othaibi for their cooperation.

\section{Funding Information}

This research was partially funded by Italian Ministry of University and Research with the project FIRB "Future in Research 2008", \# RBFR08T83J.

\section{Author's Contributions}

All the authors contributed equally to prepare, develop and carry out this manuscript.

\section{Ethics}

This article is original and contains unpublished material. The corresponding author confirms that all of the other authors have read and approved the manuscript and no ethical issues involved.

\section{References}

Aversa, R., D. Parcesepe, R.V. Petrescu, G. Chen and F.I.T. Petrescu et al., 2016a. Glassy amorphous metal injection molded induced morphological defects. Am. J. Applied Sci., 13: 1476-1482.
Aversa, R., R.V. Petrescu, F.I.T. Petrescu and A. Apicella, 2016b. Smart-factory: Optimization and process control of composite centrifuged pipes. Am. J. Applied Sci., 13: 1330-1341.

Aversa, R., F. Tamburrino, R.V. Petrescu, F.I.T. Petrescu and M. Artur et al., 2016c. Biomechanically inspired shape memory effect machines driven by muscle like acting NiTi alloys. Am. J. Applied Sci., 13: 1264-1271.

Aversa, R., R.V. Petrescu, R. Sorrentino, F.I.T. Petrescu and A. Apicella, 2016d. Hybrid ceramo-polymeric nanocomposite for biomimetic scaffolds design and preparation. Am. J. Eng. Applied Sci., 9: 1096-1105.

Aversa, R., V. Perrotta, R.V. Petrescu, C. Misiano and F.I.T. Petrescu et al., 2016e. From structural colors to super-hydrophobicity and achromatic transparent protective coatings: Ion plating plasma assisted $\mathrm{TiO}_{2}$ and $\mathrm{SiO}_{2}$ nano-film deposition. Am. J. Eng. Applied Sci., 9: 1037-1045.

Aversa, R., R.V. Petrescu, F.I.T. Petrescu and A. Apicella, 2016f. Biomimetic and evolutionary design driven innovation in sustainable products development. Am. J. Eng. Applied Sci., 9: 1027-1036.

Lockheed Martin, From Wikipedia. The free encyclopedia.

https://en.wikipedia.org/wiki/Lockheed_Martin

Lockheed C-130 Hercules, From Wikipedia. The free encyclopedia.

https://en.wikipedia.org/wiki/Lockheed_C130_Herculesa

Lockheed Martin F-35 Lightning II, From Wikipedia. The free encyclopedia. https://en.wikipedia.org/wiki/Lockheed_Martin_F35_Lightning_II

Mirsayar, M.M., V.A. Joneidi, R.V.V. Petrescu, F.I.T. Petrescu and F. Berto, 2017. Extended MTSN criterion for fracture analysis of soda lime glass. Eng. Fracture Mechan., 178: 50-59. DOI: 10.1016/j.engfracmech.2017.04.018

Petrescu, R.V. and F.I. Petrescu, 2013a. Lockheed Martin. 1st Edn., CreateSpace, pp: 114.

Petrescu, R.V. and F.I. Petrescu, 2013b. Northrop. 1st Edn., CreateSpace, pp: 96.

Petrescu, R.V. and F.I. Petrescu, 2013c. The aviation history or new aircraft I color. 1st Edn., CreateSpace, pp: 292.

Petrescu, F.I. and R.V. Petrescu, 2012. New Aircraft II. 1st Edn., Books On Demand, pp: 138.

Petrescu, F.I. and R.V. Petrescu, 2011. Memories about flight. 1st Edn., CreateSpace, pp: 652. 